\title{
Mediterranean Summer Climate and the Importance of Middle East Topography*
}

\author{
Isla R. Simpson, Richard Seager, Tiffany A. Shaw, AND Mingfang Ting \\ Lamont-Doherty Earth Observatory, Columbia University, Palisades, New York
}

(Manuscript received 22 April 2014, in final form 19 November 2014)

\begin{abstract}
In summer, the atmospheric circulation over the Mediterranean is characterized by localized intense subsidence and low-level northerlies over the central to eastern portion of the basin. Here, simulations with the Community Atmosphere Model, version 5 are used to investigate the influence of the elevated terrain of North Africa and the Middle East on this summertime circulation. This builds on previous work that recognized a role for North African topography in localizing the Mediterranean subsidence.

By flattening the two regions of elevated terrain in the model, it is demonstrated that, while they both conspire to produce about $30 \%$ of the summertime subsidence, contrary to previous work, the mountains of the Middle East dominate in this topographic contribution by far. This topography, consisting primarily of the Zagros mountain range, alters the circulation throughout the depth of the troposphere over the Mediterranean and farther east. The model results suggest that about $20 \%$ of the Mediterranean summertime moisture deficit can be attributed to this mountain-induced circulation. This topography, therefore, plays an important role in the climate of the Mediterranean and the large-scale circulation over the rest of Eurasia during the summer.

Further stationary wave modeling reveals that the mountain influence is produced via mechanical forcing of the flow. The greatest influence of the topography occurs when the low-level incident flow is easterly, as happens during the summer, primarily because of the presence of condensational heating over Asia. During other seasons, when the low-level incident flow is westerly, the influence of Middle East topography on the Mediterranean is negligible.
\end{abstract}

\section{Introduction}

The climate of the Mediterranean is influenced by a wide range of processes. Bound to the south by the arid deserts of North Africa and to the north by moist, temperate northern Europe, it lies at the boundary between two very different climate regimes. While Mediterranean-type climate zones, characterized by mild, wet winters and hot, dry summers, are found throughout the subtropics of each hemisphere, the climate of the Mediterranean itself is somewhat unique among these in the variety of large-scale dynamical factors that influence it, ranging from the North Atlantic storm track to the remote effects of the Asian monsoon (e.g., Hurrell 1995; Rodwell and Hoskins 1996, hereafter RH96). Together with the complicated orography of the region, this

* Lamont-Doherty Earth Observatory Contribution Number 7863.

Corresponding author address: Isla Simpson, Lamont-Doherty Earth Observatory, P.O. Box 1000, 61 Route 9W, Palisades, NY 10964-1000.

E-mail: isla@ldeo.columbia.edu makes it a climate that depends on many complex interactions between different components of the climate system (Lionello et al. 2006).

Global climate models predict that the Mediterranean will undergo pronounced hydroclimate and circulation changes in the future under increasing greenhouse gas concentrations (Evans 2009; Black et al. 2011; Hoerling et al. 2012; Zappa et al. 2013; Seager et al. 2014; Simpson et al. 2014). Indeed, the Mediterranean is often referred to as a climate change "hotspot" since it exhibits larger changes than many other regions of the globe (Giorgi 2006; Giorgi and Lionello 2008). Given the vulnerability of Mediterranean populations to climate change and associated changes in water resources, it is important that we have faith in these model predictions. This can be achieved through a complete understanding of the processes that govern Mediterranean climate, both in the current climate and under future climate change.

Land areas in the Mediterranean receive their moisture during the winter (Mariotti et al. 2002; Seager et al. 2014), when the region has an active local storm track over the Mediterranean sea and is also under the 
influence of midlatitude storm systems that propagate along the Atlantic storm track (Hurrell 1995; Quadrelli et al. 2001; Fernández et al. 2003). The storm systems that are generated within the Mediterranean basin itself are substantially influenced by the complex orography of the region and they feed on moisture and gain energy from the Mediterranean Sea to form the local Mediterranean storm track (Alpert et al. 1990; Trigo et al. 1999).

In transitioning to the summer season, this mild, wet, variable climate gives way to hot, dry, semiarid conditions as localized, intense subsidence is set up over much of the basin (RH96). While, like all other Mediterranean-type climate zones in the world, the western edge of the Mediterranean is under the influence of the vast subtropical anticyclone in the ocean basin to its west (Rodwell and Hoskins 2001, hereafter RH01) (i.e., the Atlantic) during the summertime, the pioneering work of RH96 has demonstrated that the subsidence over the central to eastern Mediterranean owes its existence primarily to the large-scale circulation patterns set up by the diabatic heating of the Asian monsoon (see also Tyrlis et al. 2013). This makes the Mediterranean somewhat unique among the Mediterranean climate zones of the world in terms of the dynamics that influence it.

The present study is motivated by the results of RH96, and so we now briefly summarize their analysis. Using a nonlinear, time-dependent primitive equation model, they performed idealized experiments to isolate the role of diabatic heating in the Asian monsoon region in contributing to Saharan and Mediterranean subsidence during the summer months. The model was initialized with Earth's orography and a zonal mean basic state derived from a 6-yr (1983-88) European Centre for MediumRange Weather Forecasts (ECMWF) initialized analysis. Diabatic heating perturbations were imposed and the circulation response examined in the following days, before the model went unstable with baroclinic instability. They found that the imposition of diabatic heating in the Asian monsoon region alone gave rise to subsidence to the west through the following mechanism: the monsoon diabatic heating and associated upper-level divergence leads to the generation of a Gill-type Rossby wave to the west of the heating (Gill 1980), consisting of a low-level cyclone and an upper-level anticyclone. This results in a warm thermal anomaly stretching to the west of the Monsoon heating, across the Middle East. The midlatitude westerlies then interact with this thermal structure, and the flow descends adiabatically down the isentropes that have been steepened by it. This subsidence of clear air was then hypothesized to result in a further diabatic enhancement of the subsidence. Building on this work, RH01 provided further evidence for the importance of this local diabatic enhancement and also demonstrated that the other monsoons of the world had a similar influence, resulting in downwelling and therefore closing off the eastern portion of the subtropical anticyclone in the ocean basin to their west. The Asian monsoon influence on the circulation and resulting subsidence to the west, identified by RH96, was termed the "monsoon-desert" mechanism and is clearly an integral component of the climate of the Mediterranean during summer.

In addition to proposing the monsoon-desert mechanism, RH96 also noted the importance of topography in localizing the regions of subsidence. In their model, removal of the North African topography, predominantly the Atlas Mountains, altered the structure of Mediterranean subsidence (cf. Figs. 11a,c of RH96). The circulation induced by these mountains acted to enhance the subsidence over the central to eastern Mediterranean. They also found that removal of Middle East mountains, primarily the Zagros mountain range, had little influence on the subsidence over the Mediterranean but that these mountains acted to enhance the subsidence farther east, to the south of the Aral Sea, in the Uzbekistan/Turkmenistan region. The mechanisms proposed by RH96 to explain this topographic influence can be summarized as follows: assuming westerly incident flow, an anticyclonic circulation is generated over both the Atlas and the Zagros mountain ranges with associated subsidence on its eastern flank, because of the adiabatic equatorward flow. Of relevance for the present study is that the topography had little influence to its west and it was assumed that the circulation anomalies were induced by westerly incident flow (see RH96, p. 1399).

Here, we revisit the role of topography in shaping the summertime atmospheric circulation and climate of the Mediterranean through experiments with a comprehensive global climate model (GCM). The primary focus is June-August (JJA), which, as will be shown, is the season when the topography has the greatest influence. In addition to improving our general scientific understanding of the factors that govern the climate of the Mediterranean, there is particular motivation to understand the dynamics of the region as we move toward a warmer climate. Our goal is to revisit the conclusions of RH96 using a comprehensive GCM. As will be shown below, the GCM simulations lead to different conclusions to those of RH96, in terms of the topographic influence, and highlight the importance of mountains of the Middle East in contributing to the central to eastern Mediterranean subsidence during the summer. We subsequently clarify certain aspects of the mechanism by which this topographic influence is realized: in particular, that the incident flow on the mountains is easterly, not westerly, and the subsidence in the middle to upper 
troposphere is not simply a result of the anomalous meridional flow set up by the mountains but involves interaction of the mountain-induced circulation with the midlatitude westerlies. The way in which the mountains exert their influence is, therefore, somewhat different to that hypothesized by RH96. We highlight the importance of the Middle East mountains, consisting primarily of the Zagros mountain range, for the large-scale circulation throughout the depth of the troposphere over the Mediterranean as well as farther to the east over Asia. Further, we identify the influence of the mountains on climatic quantities such as precipitation and evaporation, which were not considered in the idealized dry dynamical model simulations of RH96.

In section 2, we summarize the data used and model experiments performed. This is followed by validation of the model climatology over the Mediterranean in section 3 and a diagnosis of the mountain influence in the summer months in section 4 . In section 5, additional idealized stationary wave model experiments are used to demonstrate the mechanical influence of the mountains on the flow and the dynamical mechanism of this influence is discussed. In section 6 , it is demonstrated that the Middle East topography only has a substantial influence on circulation during the summer, when the incident low-level flow is easterly, and section 7 then examines the cause of this summertime low-level easterly incident flow. Overall discussion and conclusions are provided in section 8 and 9.

\section{Model experiments and data}

We use the Community Earth System Model (CESM) (Hurrell et al. 2013) run in stand-alone Community Atmosphere Model (CAM) mode with CAM5 physics and the finite volume dynamical core at $1.9^{\circ} \times 2.5^{\circ}$ horizontal resolution with 30 levels in the vertical up to around $3 \mathrm{hPa}$ (hereafter referred to as CAM5). While we make use of CAM5 physics, since we found this to have a better representation of the circulation in the Mediterranean region than previous model versions, our simulations do not include the CAM5 prognostic aerosol package. This is computationally cheaper without degradation to the circulation over the Mediterranean. Each model experiment is run with year 2000 greenhouse gas concentrations and prescribed 1981-2001 climatological sea surface temperatures (SSTs) and sea ice, as provided for the standard NCAR F_2000_CAM5 component set. Model output is compared with the ERA-Interim reanalysis climatologies from 1979 to 2012 (Dee et al. 2011).

Our interest here is on the topographic influence on Mediterranean circulation and, in particular, on the

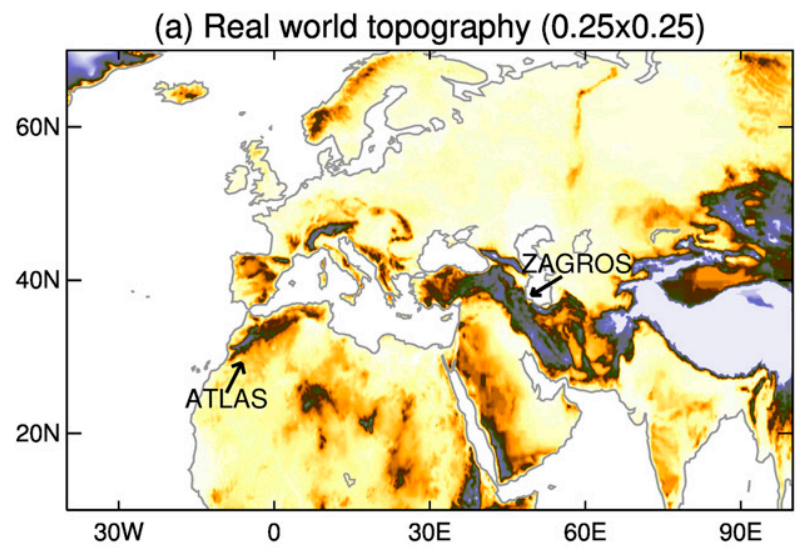

(b) CTRL topography

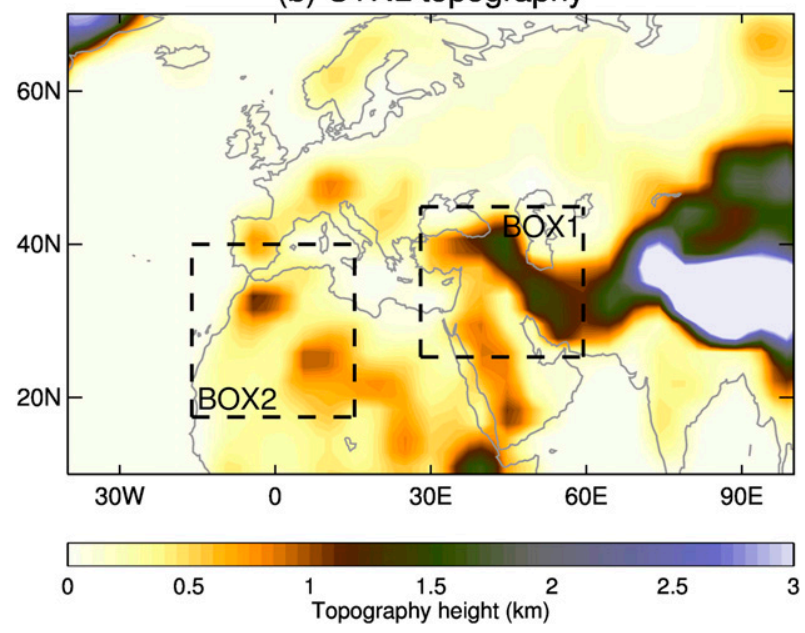

FIG. 1. (a) Real-world topography $\left(0.25^{\circ} \times 0.25^{\circ}\right.$ resolution $)$ and (b) CAM5 CTRL topography $\left(1.9^{\circ} \times 2.5^{\circ}\right.$ resolution $)$. The dashed lines in (b) encompass the two boxes in which topography is flattened in each of the experiments. Note that shading is saturated for topographic heights above $3 \mathrm{~km}$.

influence of the elevated terrain of northwest Africa and the Middle East. The dominant mountain ranges of these regions, the Atlas Mountains and the Zagros Mountains, are highlighted in the real-world topography shown in Fig. 1a. This real-world topography, on a $0.25^{\circ} \times$ $0.25^{\circ}$ grid, ${ }^{1}$ can be compared with the CAM5 topography at $1.9^{\circ} \times 2.5^{\circ}$ resolution in Fig. 1b. Clearly, the topography is smoothed on the model grid. The Zagros Mountains have many peaks over $4 \mathrm{~km}$ and Fig. 1a demonstrates a mean height of over $2 \mathrm{~km}$, whereas the model topography does not reach much over $1.5 \mathrm{~km}$. A similar smoothing of the Atlas Mountains also occurs. Despite this, it will be shown that the model does well at

\footnotetext{
${ }^{1}$ Topography data were obtained from JISAO at the University of Washington (http://www.jisao.washington.edu/datasets/elevation/).
} 
simulating the basic large-scale features of the Mediterranean circulation.

We use CAM5 to investigate the influence of regions of elevated terrain on Mediterranean circulation. Consider the two boxed regions depicted in Fig. 1b. The first (box 1) extends from $28^{\circ}$ to $60^{\circ} \mathrm{E}$ and from $25^{\circ}$ to $45^{\circ} \mathrm{N}$ and covers the Zagros Mountains as well as the Anatolian plateau to their northwest, the northern part of the Hejaz Mountains of Saudi Arabia to their southwest, and a portion of the Iranian plateau to their southeast. This is the Middle East topography considered. A sensitivity experiment in which only the smaller-scale topography over Saudi Arabia, Syria, and Iraq is flattened reveals that the influence of the topography is primarily due to the higher-altitude meridionally elongated mountain range that consists of the Zagros Mountains, ending in the Anatolian plateau in the north. Since the Zagros Mountains are the dominant feature of this region of elevated terrain, this will be referred to as the Zagros Mountain influence throughout. The second (box 2) extends from $17^{\circ} \mathrm{W}$ to $15^{\circ} \mathrm{E}$ and from $17^{\circ}$ to $40^{\circ} \mathrm{N}$ and covers the North African topography, in particular the Atlas Mountains but also the Ahaggar range to the southeast and part of the elevated terrain of Spain. The Atlas Mountains are the dominant feature of this region and so this will be referred to as the Atlas Mountain influence throughout.

The following four experiments were each initialized from default F_2000_CAM5 component set initial conditions and run for $100 \mathrm{yr}$ after disregarding the first $3 \mathrm{yr}$ :

- CTRL $=$ a control experiment with the default topography boundary conditions;

- BOTHFLAT = both boxes 1 and 2 are flattened;

- ZAGFLAT = box 1 is flattened; and

- $\mathrm{ATFLAT}=$ box 2 is flattened.

The nomenclature refers to the dominant mountain range being flattened: Zagros (ZAG), Atlas (AT), or both (BOTH). In the flattened regions, the elevated terrain is reduced to $100 \mathrm{~m}$, while leaving the standard deviation of topography (an input to the orographic gravity wave drag parameterization scheme) unaltered. These experiments were originally performed with an older model (CAM3) with a slab ocean and a spectral dynamical core at $\mathrm{T} 42$ resolution and all conclusions to be presented here are valid for those simulations as well, lending support to their robustness.

In sections 5 and 7, these comprehensive GCM experiments are complemented with idealized simulations with a stationary wave model. This model, described in detail in Ting and Yu (1998), is a fully nonlinear, timedependent baroclinic model with 14 sigma levels in the vertical and spectral R30 horizontal resolution. It solves the nonlinear primitive equations for deviations from a prescribed basic state to obtain the equilibrium response to given forcings. We will refer to this as the stationary wave model. Rayleigh friction is applied on the lowest four levels with time scales of $(1,0.5,0.25$, $0.15)$ days (shortest time scale at the surface). A Newtonian relaxation of the temperature field toward the prescribed basic state is applied on pressure surfaces with a time scale of 15 days and biharmonic diffusion is applied with a coefficient of $1 \times 10^{17}$ in order to suppress baroclinic instability. The zonal wind, meridional wind and temperature (after linear interpolation onto the stationary wave model sigma coordinates), and surface pressure from the comprehensive GCM experiments are used to define the basic state and the response to the presence of topography and/or diabatic heating is examined. The model reaches a quasi-steady state by around day 20 and the average solution from days $30-80$ is used.

\section{Validation of the CAM5 Mediterranean circulation}

Before proceeding to examine the influence of the mountains in CAM5, the climatological circulation in the model is first validated against that of ERA-Interim. Figure 2 compares various aspects of the model simulation with ERA-Interim for the JJA climatology, which is our primary season of interest. The fields shown are those that will be used throughout the following to assess the mountain influence.

Figures 2a,b show 500-hPa vertical velocity for ERAInterim and CTRL, respectively (close to the level used to diagnose subsidence in RH96, which was $477 \mathrm{hPa}$ ). Three prominent regions of subsidence can be seen. In the west, the subsidence on the eastern flank of the Atlantic subtropical anticyclone is a bit too strong in the model. Farther to the east, there is a region of strong localized subsidence in the central to eastern Mediterranean, which is our main feature of interest and is well represented by the model. Another region of subsidence is located to the east of the Zagros Mountains and again compares relatively well between ERA-Interim and the model. These three regions of subsidence are separated by regions of weak ascent that coincide roughly with the Atlas and Zagros Mountains.

Throughout the following, the wind fields will be examined on the $300-$ and $700-\mathrm{hPa}$ levels. The $300-\mathrm{hPa}$ level is representative of the behavior in the upper troposphere, and the 700-hPa level is representative of the behavior in the lower troposphere but is a level that does not intercept the topography. In the upper-tropospheric meridional wind (Figs. 2c,d), wave structures can be 
(a) ERA-Interim $500 \mathrm{hPa} \omega$

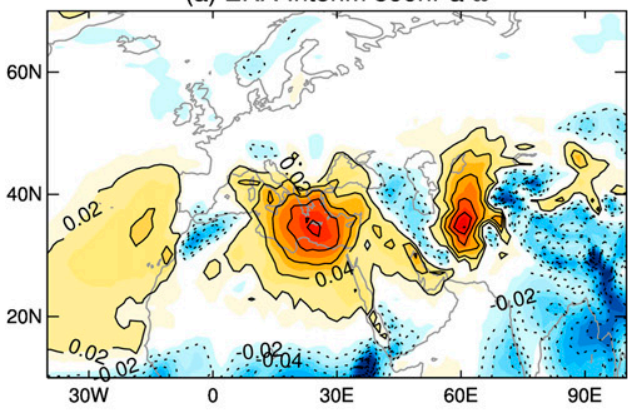

(c) ERA-Interim $300 \mathrm{hPa} \mathrm{v}$

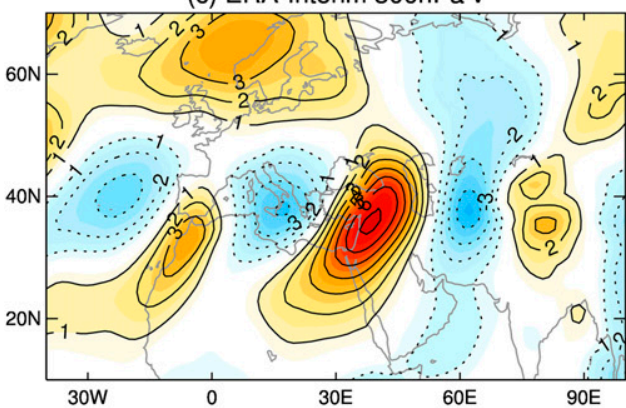

(e) ERA-Interim $700 \mathrm{hPa} v$

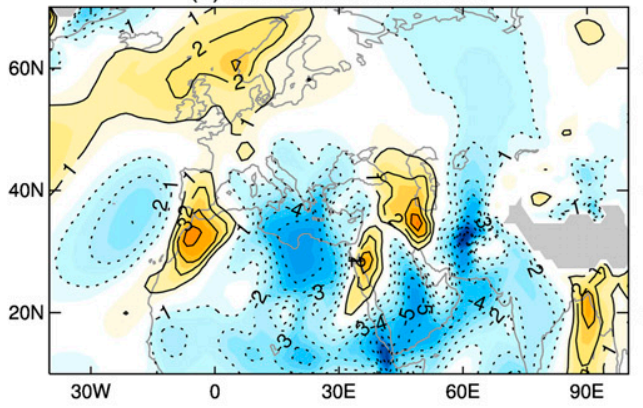

(g) ERA-Interim $700 \mathrm{hPa}$ wind vectors

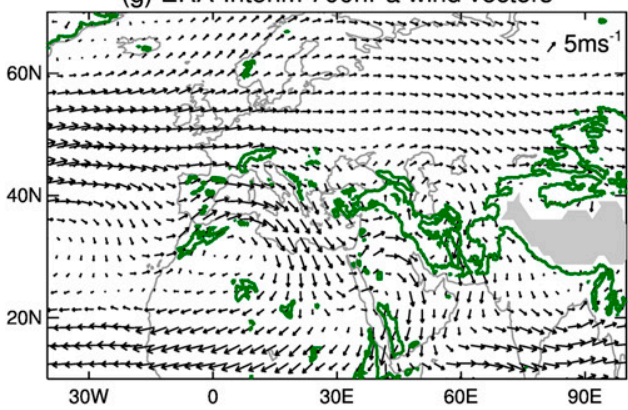

(b) CTRL 500hPa $\omega$

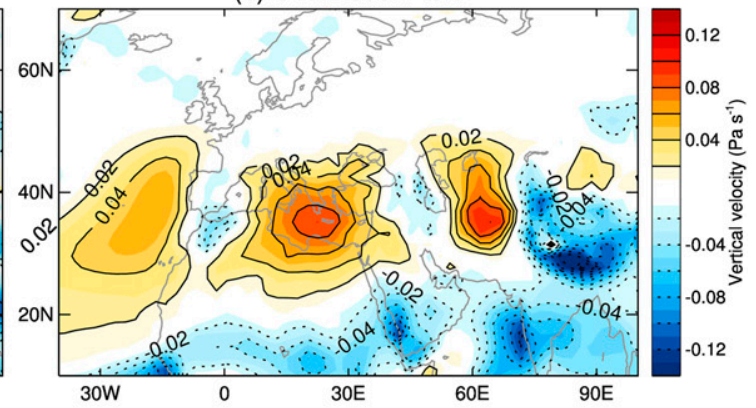

(d) CTRL $300 \mathrm{hPa} v$

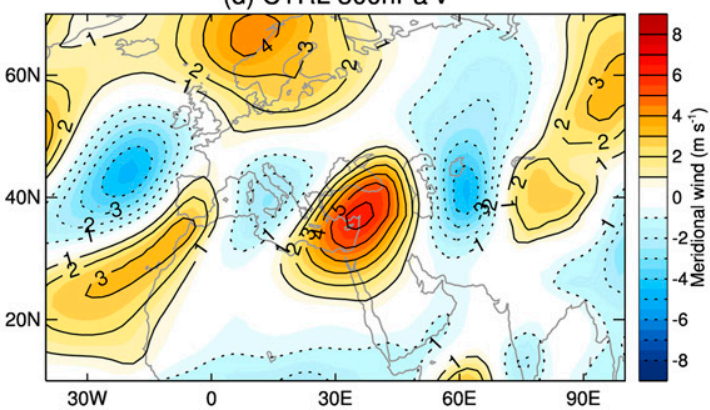

(f) CTRL 700hPa v

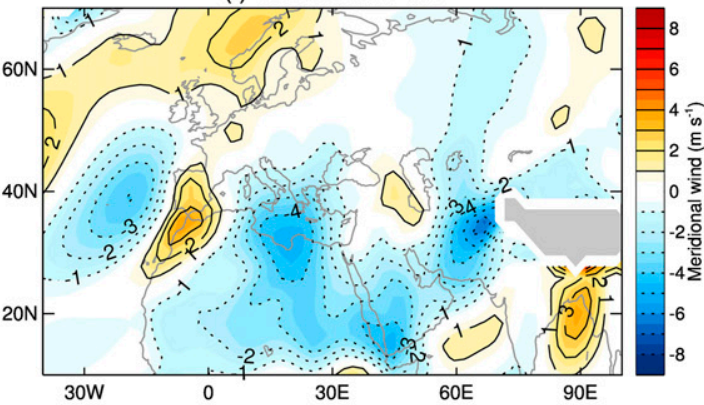

(h) CTRL 700hPa wind vectors

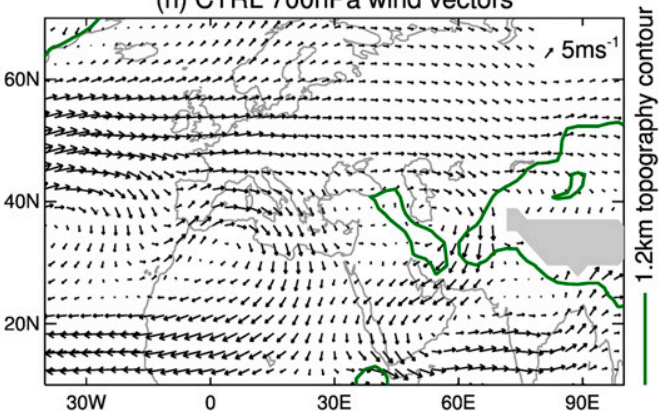

FIG. 2. Climatological JJA season averages for (left) ERA-Interim and (right) the CAM5 CTRL simulation: (a),(b) 500-hPa vertical (pressure) velocity; (c),(d) 300-hPa meridional wind; (e),(f) 700-hPa meridional wind; and (g),(h) 700-hPa wind vectors. Gray shading denotes regions that are below the surface. The green line in (g),(h) shows the $1.2-\mathrm{km}$ topography contour.

seen across the region. Much like for the vertical velocity, the northerlies in the eastern Atlantic are larger magnitude in CAM5 than in ERA-Interim. The northerlies over Italy are a bit weaker in the model and the southerlies to their east are less meridionally elongated but, overall, the model exhibits very similar features to ERA-Interim. The lower-tropospheric meridional wind at $700 \mathrm{hPa}$ in Figs. 2e,f also compares well between CAM5 and ERA-Interim. Alternating regions of southerly and northerly winds occur across the region. 


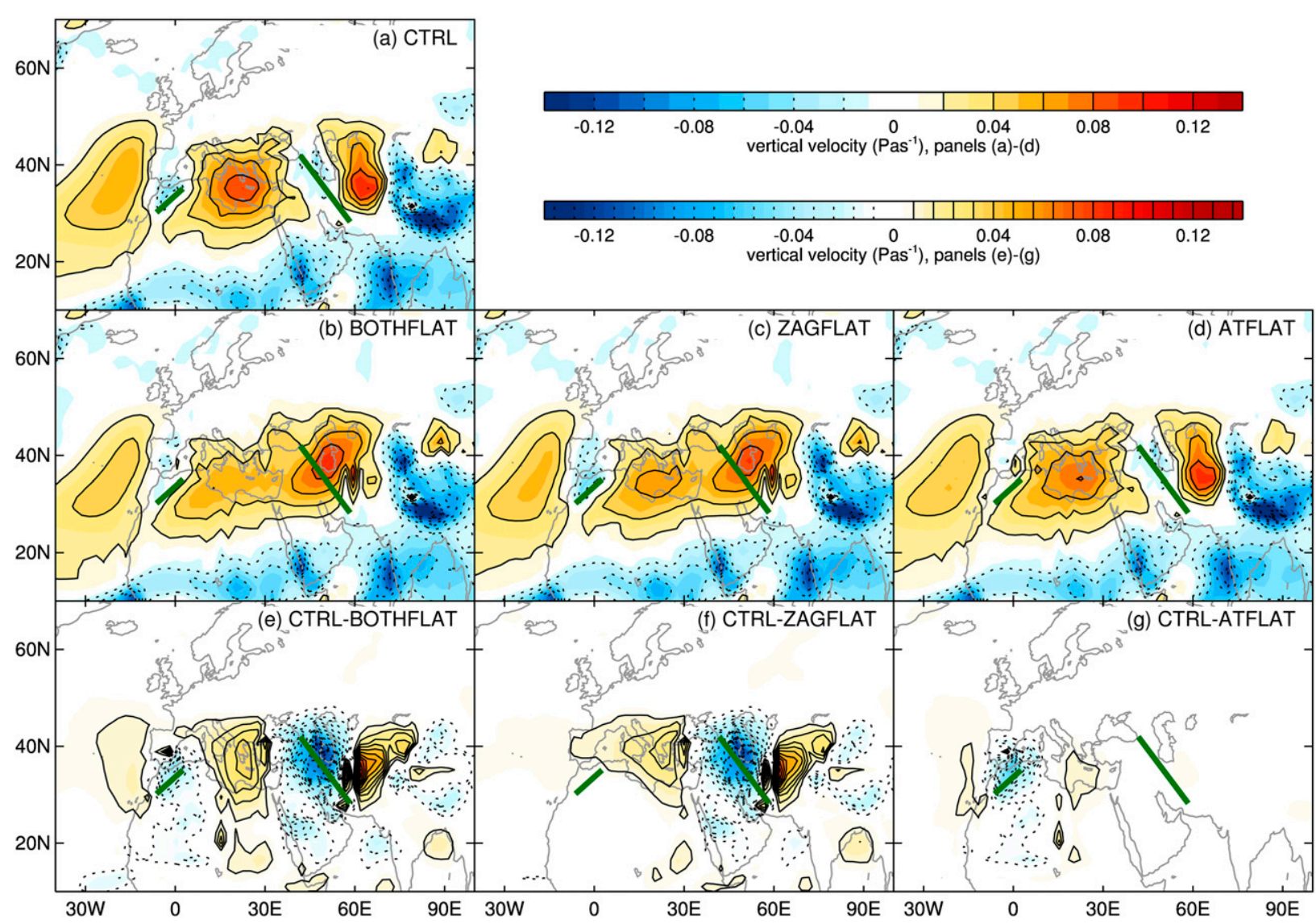

FIG. 3. JJA averaged vertical (pressure) velocity at $500 \mathrm{hPa}$ for (a) CTRL, (b) BOTHFLAT, (c) ZAGFLAT, (d) ATFLAT, (e) CTRL BOTHFLAT, (f) CTRL - ZAGFLAT, and (g) CTRL - ATFLAT. The green lines depict the approximate locations of the Zagros and Atlas mountain ranges (see Fig. 1 for the actual topography).

Strong, low-level northerlies exist in the central to eastern Mediterranean and eastern North Africa, which are separated from northerlies over the east Atlantic and east of the Caspian Sea by southerlies that approximately coincide with the Atlas and Zagros Mountains.

In addition, an overall view of the lower-tropospheric flow is given by the $700-\mathrm{hPa}$ wind vectors in Figs. $2 \mathrm{~g}$,h. This should not be considered the incident flow on the mountains as it is at a pressure level above the topography and includes the modification of the circulation by the presence of the mountains. The incident flow on the mountains is discussed in section 5 and Figs. $2 \mathrm{~g}$, h are simply used to illustrate the lower-tropospheric circulation in the presence of the mountains. The model captures the low-level circulation relatively well, including the anticyclonic circulation to the east of the Zagros Mountains. The flow over Mesopotamia/Saudi Arabia is not well represented in the model. In ERAInterim, relatively strong westerlies are seen over northern Saudi Arabia, which turn southward toward the Indian Ocean, and in CAM5 the winds there are weak. This aspect of the circulation is improved with a higher $\left(0.9^{\circ} \times 1.25^{\circ}\right)$ resolution (not shown) but because of computational constraints it was not possible to perform all the experiments here at that resolution. However, some shorter sensitivity tests with this resolution were performed and these suggest that the same conclusions as to the topography influence on the largescale circulation will hold at a higher resolution.

In summary, CAM5 at $1.9^{\circ} \times 2.5^{\circ}$ resolution exhibits a good representation of the main features of the largescale circulation over the Mediterranean and so we can proceed to use it to investigate the topographic influence.

\section{The mountain influence}

\section{a. The influence on the large-scale circulation}

We begin by assessing the influence of topography on 500-hPa vertical velocity in Fig. 3. Significance has not been plotted here, or in the subsequent figures, but it has 
been tested and anomalies to which we refer are statistically robust, beyond the $99 \%$ level. Beginning with the BOTHFLAT simulation, it is clear by comparison of Figs. 3a,b that the presence of the topography has a substantial influence on the midtropospheric subsidence. The subsidence that can be attributed to the topographic influence (i.e., the difference between CTRL and BOTHFLAT) is shown in Fig. 3e. The topography enhances the subsidence center over the central to eastern Mediterranean, and these model results suggest that, if these mountain ranges were not there, the strength of this subsidence center would be weaker on average by roughly $30 \%$. Without the mountains (Fig. 3b), we are left with maximum subsidence over the Zagros location, which extends into a broad region of subsidence over the eastern and central Mediterranean. This is presumably the subsidence induced by the RH96 monsoon-desert mechanism, which, in the model with full topography and in the real atmosphere, has a substantially altered structure over both the Mediterranean and Middle East, because of the topography.

Looking more closely at the Zagros Mountain influence (Figs. 3c,f), they induce a tripole vertical velocity pattern that is apparent throughout the depth of the troposphere (not shown). The Zagros Mountains result in ascent at their location and enhanced subsidence to their east (in agreement with RH96), but they also contribute to a substantial fraction of the subsidence to their west, over the central to eastern Mediterranean. This important role for the Zagros Mountains in contributing to central to eastern Mediterranean subsidence is in contrast to the results of RH96. The Atlas Mountains (Figs. 3d,g) have a generally weaker influence, but they also result in a tripole vertical velocity pattern, similar to the Zagros, with enhanced subsidence to their west and east and ascent over their location. Given this tripole response and the spacing of the Atlas and the Zagros Mountains, both mountain ranges conspire to produce subsidence over the same location (around Greece). However, in contrast to RH96, the contribution from the Zagros Mountains dominates in this region. The CTRL - ZAGFLAT and CTRL - ATFLAT differences approximately add up to the CTRL BOTHFLAT difference, indicating that the effects of the two mountain ranges are approximately linearly additive with nonlinear interaction between the responses to the individual mountain ranges playing only a minor role.

For brevity, since the Zagros Mountains are the dominant contribution here to the topographic influence on central to eastern Mediterranean summertime subsidence, we will continue to focus primarily on their influence. Figure 4 demonstrates the influence of the Zagros Mountains on lower-tropospheric $(700 \mathrm{hPa})$ and upper-tropospheric $(300 \mathrm{hPa})$ winds. The meridional wind in the absence of the Zagros Mountains in Figs. 4a,d can be compared with the full topography case in Figs. 2f,d. In the lower troposphere (Fig. 4b), the Zagros Mountains induce a tripole pattern of meridional wind, with southerlies along their axis and northerlies to their west and east. A similar but weaker tripole meridional wind pattern is produced by the Atlas Mountains (not shown) and the spacing of the two mountain ranges is actually such that both act to produce northerlies over the central to eastern Mediterranean and North Africa, with the Zagros Mountains being more important to the north over the Mediterranean but the Atlas Mountains being of comparable importance over North Africa.

At upper levels, in the absence of the Zagros Mountains (Fig. 4d), the meridional wind over the Middle East is characterized by a broad region of southerlies, which lie on the western flank of the upper-level anticyclone, associated with the Asian monsoon. It is clear from Fig. $4 \mathrm{e}$ and comparison of Figs. $4 \mathrm{~d}$ and $2 \mathrm{~d}$ that the $\mathrm{Za-}$ gros Mountains play an important role in shaping the upper-tropospheric meridional wind structure over Eurasia. The mountains result in a wave train that extends toward the east along the Asian jet (Fig. 4e) and, over the Middle East, the presence of this wave train actually causes the upper-level meridional wind to change sign from about $4 \mathrm{~ms}^{-1}$ southerly to $4 \mathrm{~ms}^{-1}$ northerly. In addition to this large-amplitude wave train along the Asian jet, there is a secondary, weaker wave train that extends toward the east over northern Europe. Again, the Atlas Mountains produce a similar but weaker upper-tropospheric wave train that extends toward the east over the Mediterranean (not shown).

The overall structure of the circulation induced by the Zagros Mountains is further demonstrated by the wind vectors in Figs. 4c,f, indicating that the mountains produce a low-level anticyclonic circulation to the east of the range and a cyclonic circulation to the west, along with the upper-level tilted wave train that extends toward the east along the Asian jet.

\section{b. The influence on the summer hydroclimate of the Mediterranean}

Here, the Zagros Mountain influence on quantities of hydroclimatic relevance over the Mediterranean basin, precipitation $(P)$ and evaporation $(E)$, will be discussed. In the summer, the Mediterranean region is in moisture deficit with very little precipitation (Fig. 5a), substantial evaporation (Fig. 5c), and therefore an overall negative $P-E$ (Fig. 5e). The contribution of the Zagros Mountains to this, determined from the CTRL - ZAGFLAT 
$700 \mathrm{hPa}$

(a) ZAGFLAT, V

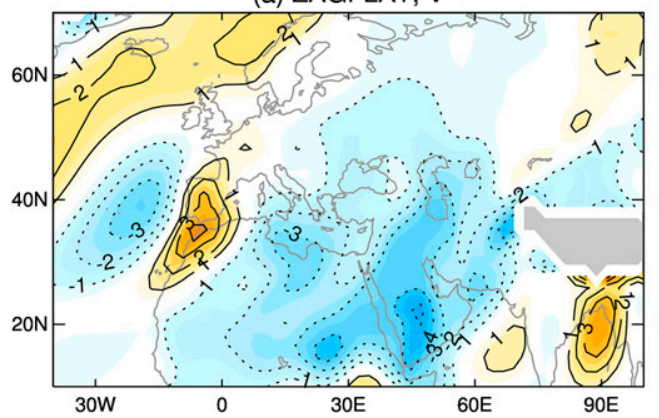

(b) CTRL-ZAGFLAT, V

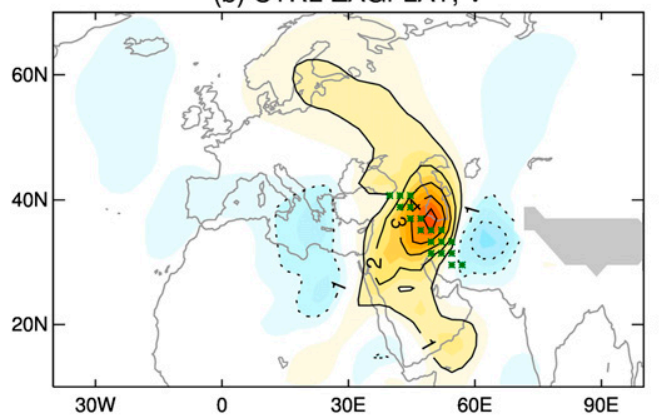

(c) CTRL-ZAGFLAT, wind vectors

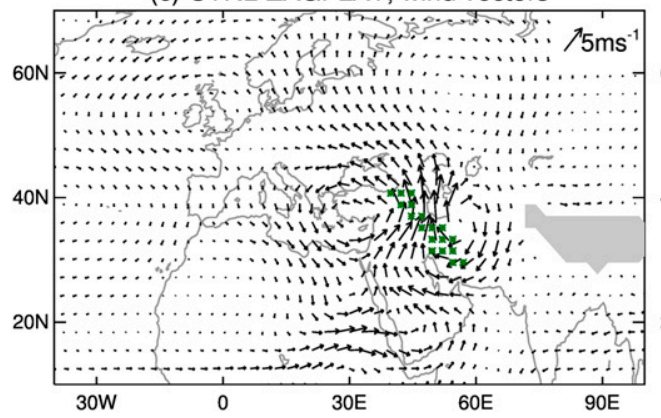

$300 \mathrm{hPa}$

(d) ZAGFLAT, V

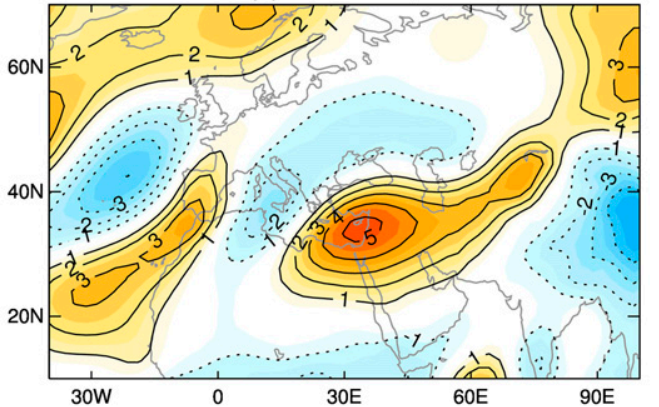

(e) CTRL-ZAGFLAT, V
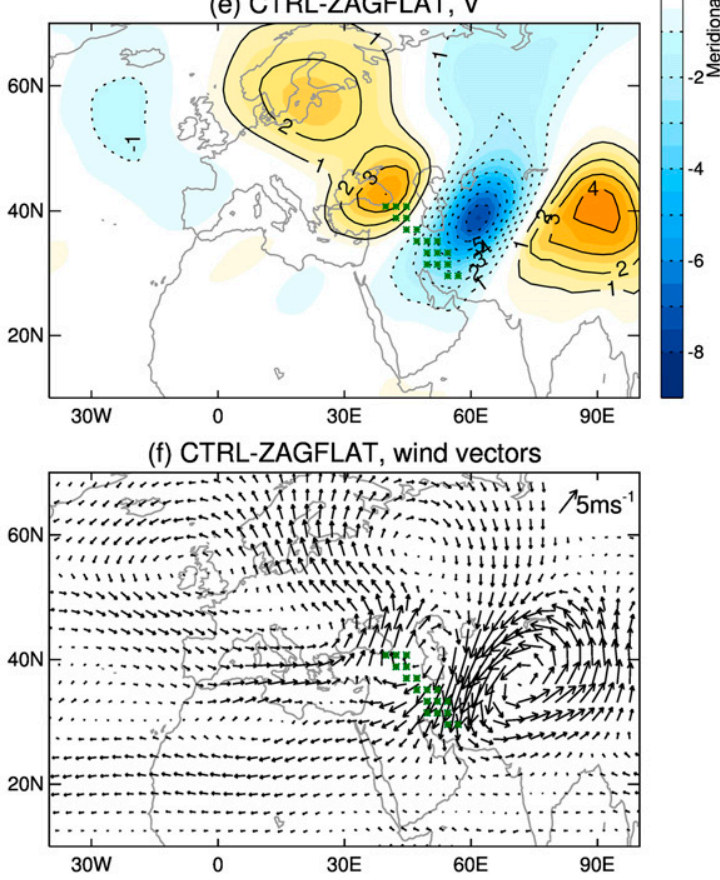

FIG. 4. (a) ZAGFLAT 700-hPa meridional wind and (b) the influence of the Zagros Mountains on 700-hPa meridional wind (i.e., CTRL - ZAGFLAT). (c) As in (b), but showing wind vectors. (d)-(f) As in (a)-(c), but at $300 \mathrm{hPa}$. The green points in (b)-(f) indicate the position of the Zagros Mountains by showing grid points in the region that are above $1.2 \mathrm{~km}$, and gray shading denotes regions that are below the surface.

difference, is shown in Figs. 5b,d,f. The large anomalies centered around $40^{\circ} \mathrm{N}, 40^{\circ} \mathrm{E}$ are in the region where topography has been changed, and so they are a direct local consequence of the flattened topography. However, anomalies over the Mediterranean to the west are also seen, associated with the Zagros-induced circulation.

Over the Mediterranean basin the Zagros Mountains have very little influence on $P$ (Fig. 5b). The only regions where $P$ does change are those where climatologically there is some summertime precipitation, such as over the Balkans and northeastern Spain. In these regions the Zagros Mountain-induced subsidence acts to suppress precipitation. However, the greatest influence of the mountains is on evaporation (Fig. 5d). They act to enhance $E$ over much of the basin and therefore result in an overall enhancement of the moisture deficit of the region. For $P-E$, in most places where red shading is present in Fig. 5 f, the magnitude is roughly $20 \%$ of the climatology.

In the presence of the Zagros Mountains, the enhanced subsidence and associated low-level divergence result in an enhanced divergence of moisture away from the Mediterranean. This is partially offset by the enhanced northerly flow that advects moister air from the north, but the subsidence effect wins out to produce a net moisture flux divergence by the large-scale flow that balances the increased excess of $E$ over $P$. 
(a) P, CTRL

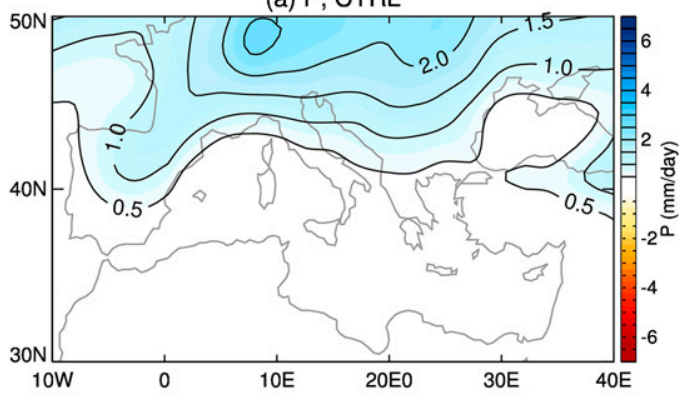

(c) E, CTRL

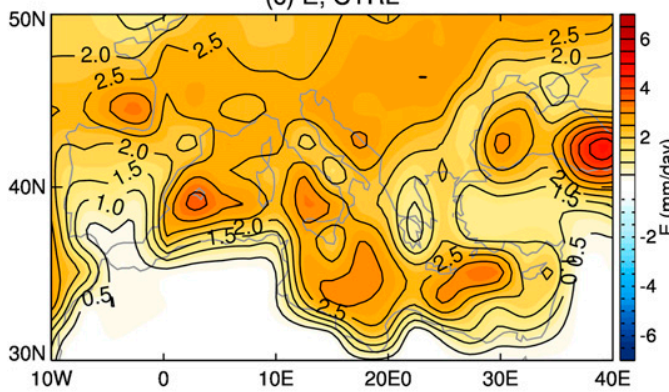

(e) P-E, CTRL

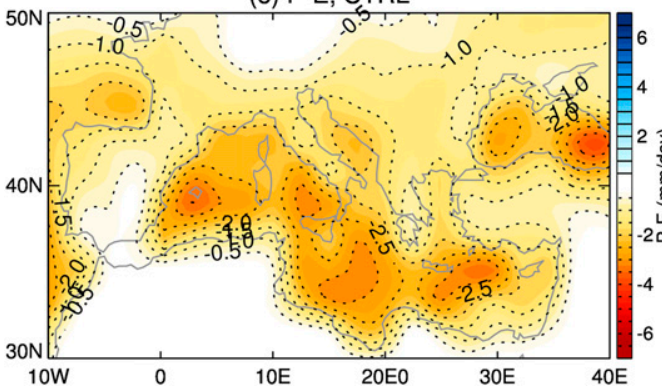

(b) P, CTRL-ZAGFLAT

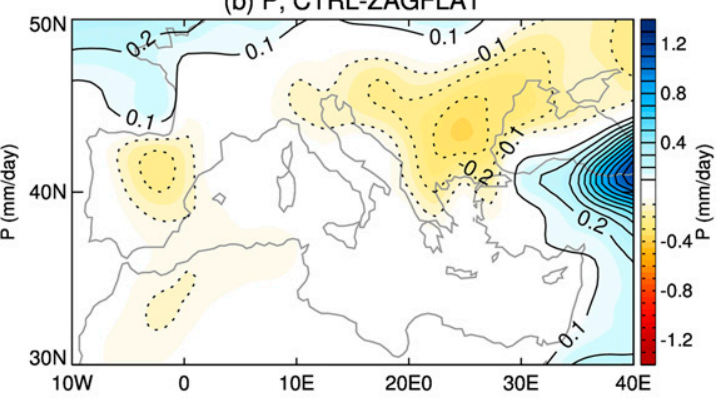

(d) E, CTRL-ZAGFLAT

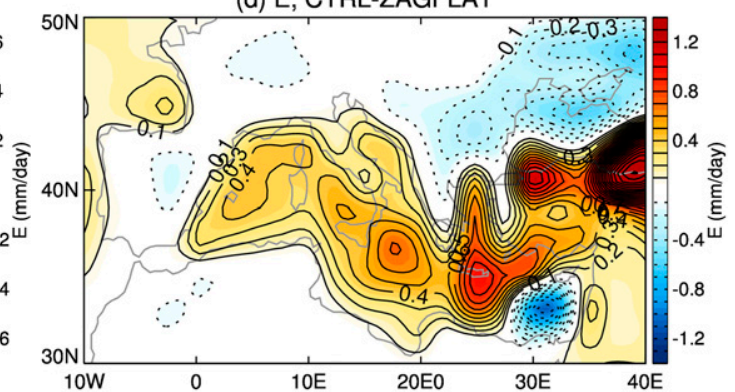

(f) P-E, CTRL-ZAGFLAT

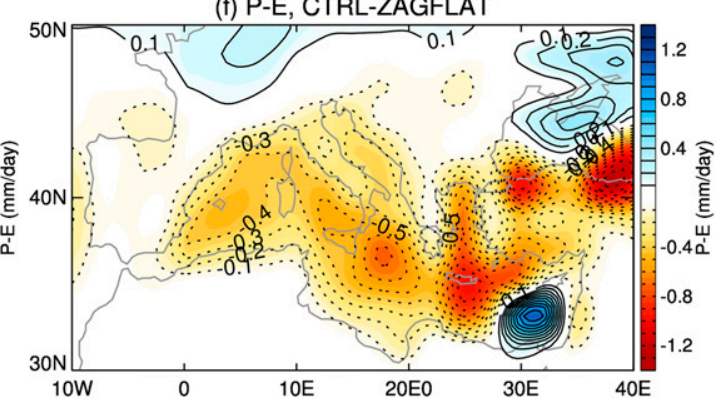

FIG. 5. Precipitation, evaporation, and precipitation - evaporation in units of millimeters per day. (a),(c),(e) Values for the CTRL JJA climatology and (b),(d),(f) values for the CTRL - ZAGFLAT JJA climatology: that is, the influence of the Zagros Mountains. Color bars are in the sense that moistening is blue and drying is red. The contour interval for the anomalies is $20 \%$ of the contour interval of the CTRL climatology; for plotting purposes, on this more regional scale, model output has been interpolated onto a finer $\left(0.5^{\circ}\right)$ grid using a cubic spline interpolation.

Evaporation depends on the near surface wind magnitude and near surface specific humidity and so changes in $E$ can be caused by anomalies in either of these quantities. The enhanced $E$ in the eastern side of the basin is primarily driven by an increase in the near surface wind magnitude (not shown) as the Zagros Mountains induce low-level northerlies that enhanced the climatological northerly winds there (as seen at $700 \mathrm{hPa}$ in Fig. 4b). Near the surface, the enhanced northerlies maximize around the longitude of Crete, resulting in the local maximum in enhanced $E$ in that region, although the coarse model resolution means this is dominated by only a few grid points and so caution should be used when interpreting these regional features. In addition to this, there is a reduced near surface specific humidity over much of the basin and the land to the north (not shown) due to the subsiding drier air. This results in enhanced evaporation and dominates to the west of Italy but is of secondary importance compared to the enhanced surface winds in the eastern part of the basin.

Overall, on the basinwide scale, roughly $20 \%$ of the moisture deficit over the Mediterranean in the summer months can be attributed to the Zagros-induced circulation that acts to enhance the low-level divergence of moisture away from the region, which balances enhanced evaporation. Here, SSTs have been prescribed, and it could be expected that the Zagros influence on $E$ may be modified if the SSTs were allowed to respond. However, the slab ocean experiments with the older model, CAM3, produced very similar $E$ anomalies (not shown) and so the limitation of prescribed SSTs is unlikely to impact on these conclusions. 
If one considers only the grid points that are over the Mediterranean Sea, then the $P-E$ in CTRL is around $-2.3 \mathrm{~mm} \mathrm{day}^{-1}$, whereas the $P-E$ in ZAGFLAT is around $-1.9 \mathrm{~mm}$ day $^{-1}$. Over the entire Mediterranean Sea, this is roughly equal to $0.0027 \mathrm{~Sv}(1 \mathrm{~Sv} \equiv$ $10^{6} \mathrm{~m}^{3} \mathrm{~s}^{-1}$ ), which is approximately equivalent to the discharge of four Nile Rivers (before it was modified for irrigation purposes). Negative $P-E$ over the Mediterranean Sea is balanced by net inflow of water from the Atlantic Ocean through the Strait of Gibraltar, an exchange that also exports salt to the Atlantic. Hence, the Zagros Mountains likely also have an influence on the salinity and circulation of the Atlantic Ocean. However, such impacts are beyond the scope of the current work.

\section{The mechanical influence of the mountains}

\section{a. Confirmation of a mechanical influence with the stationary wave model}

The above analysis has demonstrated the important role for topography, in particular the Zagros Mountains, in shaping the circulation over the Mediterranean during summertime as well as altering the circulation toward the east. There is a number of ways in which mountains can influence the circulation. One is through their mechanical effect: that is, the presence of the mountain barrier alters the flow of the winds that are incident upon it. Another possibility is that the mountain range acts as an elevated heat source as the land surface emits energy to the atmosphere through sensible, radiative, and latent heat fluxes, which heats the atmosphere over elevated terrain more than adjacent areas, resulting in a thermally driven circulation. Indeed, a number of studies have discussed the influence of the Zagros Mountains as an elevated heat source for the circulation on a more regional scale (Zaitchik et al. 2007; Zarrin et al. 2011). It is also possible that the mountain influence on the flow alters the transport of moisture, resulting in further latent heating influences, as identified to be important for the Himalayas by Boos and Kuang (2010).

Idealized simulations with the stationary wave model can determine whether the mechanical influence of the Zagros Mountains dominates for the large-scale features discussed: namely, the localized subsidence over the central to eastern Mediterranean, the tripole pattern in lower-tropospheric meridional wind, and the uppertropospheric wave train. The basic state imposed in the model is the three-dimensional JJA climatology for the run without the mountain range present (i.e., ZAGFLAT). The anomalies generated in the model by the presence of the surface geopotential perturbation of the mountain range are then examined. The incident flow on the mountains and the mountain perturbation imposed in the model can be seen in Fig. 6a. The winds here are shown at $850 \mathrm{hPa}$, which is a level that intercepts the topography. This can be considered the incident flow for the mountains as it is the flow that would be there if the mountains were not present. This makes clear that the incident flow for the Zagros Mountains during this season is easterly. While we cannot determine the true incident flow in the real world as the mountain influence is already present in the circulation, it can be seen that similar low-level easterly winds are also found on the eastern side of the Zagros Mountains in the reanalysis (Fig. 6b).

The stationary wave model solves the nonlinear primitive equations in the presence of the mountains at the lower boundary within the ZAGFLAT basic state. It has no representation of physical processes such as radiation, land surface processes, or latent heat fluxes and is therefore not capable of simulating the elevated heat source influence or latent heating effects. We also do not impose any diabatic heating anomalies or forcing due to transient fluxes. Therefore, if the stationary wave model, run in this configuration, can reproduce the main features of the circulation response to the mountains found in the full GCM, then this will indicate that it is the mechanical forcing by the mountains that is important and that nonlinear interactions between the mountain mechanical forcing and altered transient eddy momentum fluxes or diabatic heating are not big players in the response.

Figures $6 \mathrm{c}-\mathrm{e}$ show the $500-\mathrm{hPa}$ vertical velocity, $700-\mathrm{hPa}$ meridional wind, and 300-hPa meridional wind responses to the presence of the Zagros Mountains in the threedimensional ZAGFLAT basic state, as simulated by the stationary wave model. This can be compared with the full GCM response in Figs. 3f and 4b,e. The main features are well reproduced by simply imposing the surface geopotential perturbation of the mountains within the basic state of the mountainless simulation. The response is too large within the vicinity of the mountain, but we do not expect complete replication of the full GCM response given the simplicity of the model. For example, idealized dampings are used that do not necessarily reflect the true dampings that the full GCM experiences.

Similar responses are also found in a linear simulation in which the mountain height is scaled down by a factor of 1000 and the response is then scaled back up (not shown), which suggests that nonlinear dynamics are not necessary for interpretation of the mountain influence in this easterly incident flow. This is in contrast to larger mountain ranges, such as the Rockies or Andes, for 
(a) ZAGFLAT, $850 \mathrm{hPa}$ wind vectors

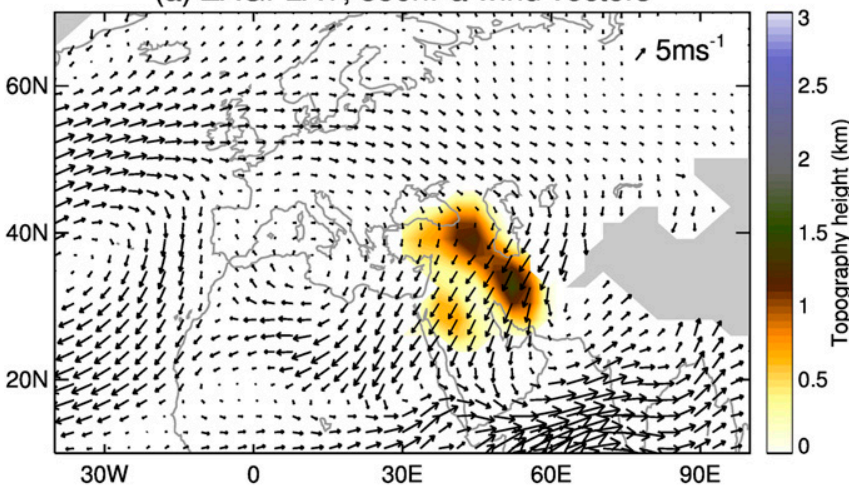

(b) ERA-Interim, $850 \mathrm{hPa}$ wind vectors

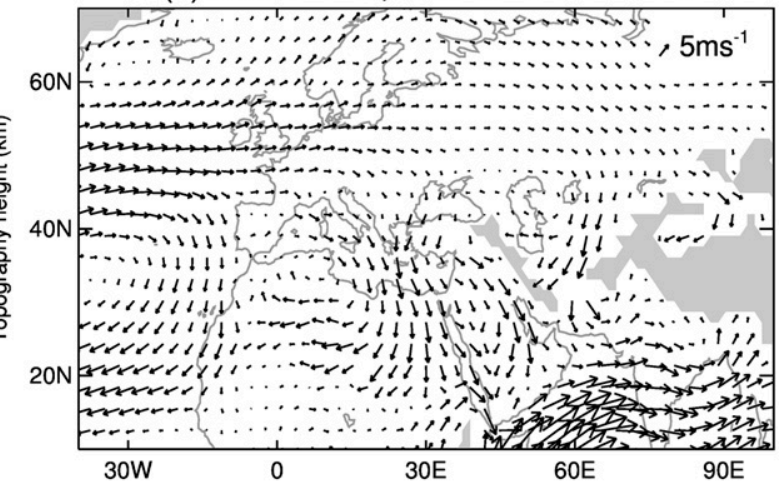

(c) $500 \mathrm{hPa} \omega$ response

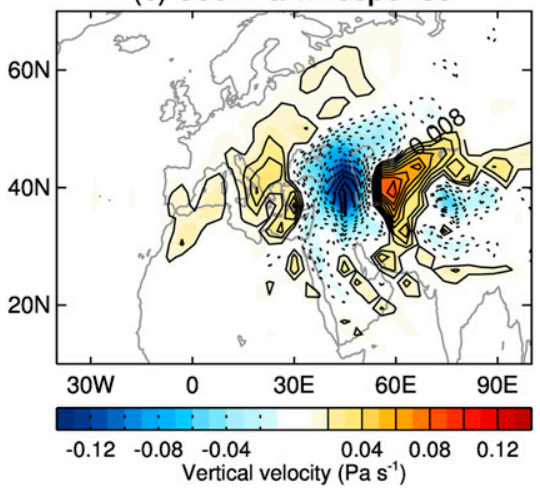

(d) $700 \mathrm{hPa} \vee$ response

(e) $300 \mathrm{hPa} v$ response
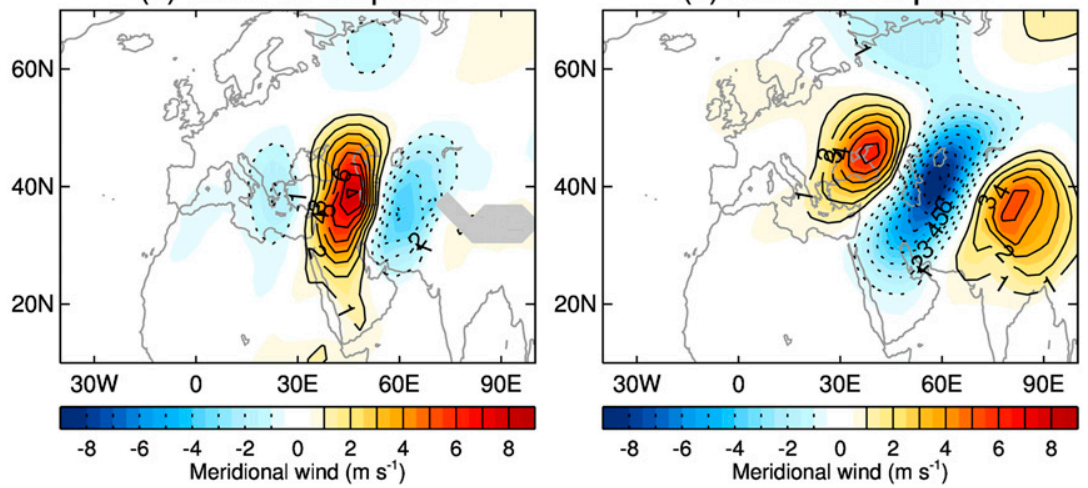

FIG. 6. (a) ZAGFLAT wind vectors at $850 \mathrm{hPa}$ : that is, the low-level winds of the basic state used for the stationary wave model experiments in section 5a. Shading denotes the topography perturbation imposed in the stationary wave model experiment. (b) The 850 -hPa wind vectors for ERA-Interim. The stationary wave model response in (c) 500-hPa $\omega$, (d) 700-hPa $v$, and (e) $300-\mathrm{hPa} v$ to the presence of the Zagros Mountains in the ZAGFLAT basic state. These can be compared with Figs. $3 \mathrm{f}$ and $4 \mathrm{~b}$,e. Gray shading denotes regions that are below the surface.

which RH01 found that nonlinear dynamics had to be considered to understand their influence on the circulation during the summer.

In summary, this stationary wave model experiment demonstrates that it is the mechanical forcing of the flow by the mountain range that is responsible for these largescale circulation features and, while the mountain influence on transient eddies or diabatic heating may modify the response slightly or may be important on a more regional scale (Zaitchik et al. 2007; Tyrlis et al. 2013), these effects are not key to the features of interest here.

\section{b. Understanding the mechanical influence of the mountains on the circulation}

In light of the above stationary wave model results, we now proceed to discuss the dynamics of the mountain influence by considering how the presence of the mountain in the mountainless basic state results in the response. The influence of topography on the large-scale flow is a topic that has received considerable attention, dating back to Charney and Eliassen (1949). Much of this attention has been focused on large-scale, midlatitude mountain ranges in westerly flow, such as the Rockies and the Himalayas (Dickinson 1978; Grose and Hoskins 1979; Hoskins and Karoly 1981; Trenberth and Chen 1988; Cook and Held 1992; Valdes and Hoskins 1991; Ringler and Cook 1997), while Semazzi (1980) discussed the response to topography in the tropics and RH01 discussed the flow over subtropical topography that is influenced by both the midlatitude westerlies and the lower-latitude easterly trade winds.

In general, the commonly studied case of westerly flow over large-scale midlatitude topography tends to produce an upstream anticyclonic circulation associated with vortex compression on the upslope and a downstream cyclonic circulation associated with vortex stretching on the downslope (e.g., Hoskins and Karoly 1981; Ringler and Cook 1997; Held et al. 2002), with the exact location of the anomalies influenced by dissipation (Hoskins and Karoly 1981). This is indeed the response predicted when considering the simple case of shallowwater westerly flow over a mountain range, as discussed by Holton (2004) (see their Fig. 4.9). This is also similar to the response we find here to easterly flow that 
produces an anticyclonic circulation upstream and a cyclonic circulation downstream of the mountain. However, the dynamics involved for easterly incident flow has received much less attention and the shallow-water arguments of Holton (2004) (their Fig. 4.10) suggest an asymmetry between westerly and easterly flow induced by the beta effect with easterly flow producing a high centered over the mountain range. The response described in Holton (2004) does not include the effects of baroclinicity, which are key to the response to the $\mathrm{Za}$ gros Mountains, as discussed below. The basic state incident flow, the size and shape of the mountain, and whether linear or nonlinear or barotropic or baroclinic theory is considered can lead to diversity in the circulation response and so we proceed to discuss the details for our particular mountain situation. As will be shown, this involves consideration of a meridionally elongated mountain range in a baroclinic atmosphere, where the low-level incident flow on the mountains is easterly and transitions to westerlies above. Again, this will be discussed from the perspective of the Zagros Mountain influence, but a similar interpretation holds for the Atlas Mountains, which also experience easterly incident flow during the summer.

Figure 7 shows various fields from the CAM5 experiments, which are helpful to gain a complete understanding of the Zagros Mountain influence and the ultimate cause of the mountain influence on central to eastern Mediterranean subsidence. These plots are focused on the Zagros location. Interpretation is further aided by consideration of the schematic depictions in Fig. 8 and the thermodynamic budget terms presented in Fig. 9. First, consider the flow that is incident on the Zagros Mountains region in the ZAGFLAT run as was shown in Fig. 6a. The zonal cross section along $39^{\circ} \mathrm{N}$, of the zonal component of the flow (Fig. 7a), makes clear that the incident flow is easterly at all pressure levels that intercept the topography, not westerly, as was assumed by RH96.

While the Zagros Mountains are slightly tilted from southeast to northwest and the incident flow is in a northeasterly direction, we simplify matters and consider easterly flow incident on a meridionally oriented mountain range, which then transitions to westerlies above, as depicted in Fig. 8a. We begin with similar arguments to those of RH01, where adiabatic flow is considered in an atmosphere where isentropes slope downward from north to south. Figure $7 \mathrm{~b}$ shows a meridional cross section of potential temperature for the ZAGFLAT basic state, demonstrating the meridionally sloping isentropes of the region.

It is instructive to first consider the lower troposphere that experiences the direct influence of the mountains.
The presence of anomalous southerlies on the upslope of the mountain, as seen in Fig. 4b, can be expected from both vorticity and thermodynamic considerations. Consider the vorticity of an air parcel approaching the mountain range and assume the rate of change of vorticity of the air parcel obeys the quasigeostrophic vorticity equation,

$$
\frac{D(\zeta+f)}{D t} \approx f \frac{\partial \omega}{\partial p},
$$

where $D / D t$ is the horizontal Lagrangian derivative following the flow, $\zeta$ is the relative vorticity, $f$ is the planetary vorticity (Coriolis parameter), $\omega$ is vertical (pressure) velocity, and $p$ is pressure. On the upslope of the mountain range, an upward (negative) vertical velocity is produced. This maximizes in the lower troposphere, around $900 \mathrm{hPa}$ (not shown), and so above this $\partial \omega / \partial p<0$, as seen in Fig. 7c: that is, there is vortex compression and horizontal divergence, which must result in a decrease in the absolute vorticity resulting in turning toward the north, as depicted schematically in Figs. $8 \mathrm{~b}, \mathrm{c}$ at point $\mathrm{A}$. This must also happen from thermodynamic considerations. If the flow is adiabatic, then if it is to flow up over the mountain range, it must also head north to flow up the meridionally sloping isentropes. As the flow heads north, $f$ increases; therefore, $\zeta$ must decrease further, resulting in further turning toward the right. The overall result on the upslope side can be seen in Figs. $7 \mathrm{~d}$ and $4 \mathrm{c}$ and schematically in Figs. 8b,c, which demonstrate an anticyclonic vorticity anomaly to the east (on the upslope) of the mountain. ${ }^{2}$

While some of the flow may turn back on itself by having gained sufficient anticyclonic vorticity, some makes it over the range. The opposite then occurs on the downslope. The subsidence maximizes near the surface and above $\partial \omega / \partial p>0$ : that is, there is vortex stretching and cyclonic vorticity generation and the flow turns toward the south, as depicted at point B in Figs. 8b,c. As the flow heads south, $\zeta$ must increase to compensate for the decreasing $f$ and further cyclonic vorticity is gained. The result is a cyclonic circulation on the western side of the northern portion of the range (Figs. 7d, 4c, and 8c).

The net result of the flow over the topography in the lower troposphere is an anticyclonic circulation to the east and a cyclonic circulation to the west, resulting in a tripole in meridional wind: southerlies along the mountain range and northerlies to the east and west, as

\footnotetext{
${ }^{2}$ Note that these circulation anomalies are not well described by Sverdrup balance as the anomalous $\partial \omega / \partial p$ in Fig. $7 \mathrm{c}$ and the anomalous meridional wind in Fig. $4 \mathrm{~b}$ do not coincide, indicating a more complex local vorticity balance.
} 
(a) ZAGFLAT u (39N)

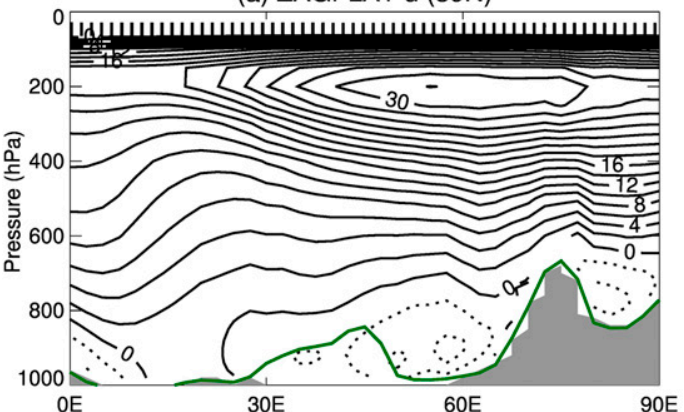

(c) CTRL-ZAGFLAT, d $\omega / \mathrm{dp}, 700 \mathrm{hPa}$

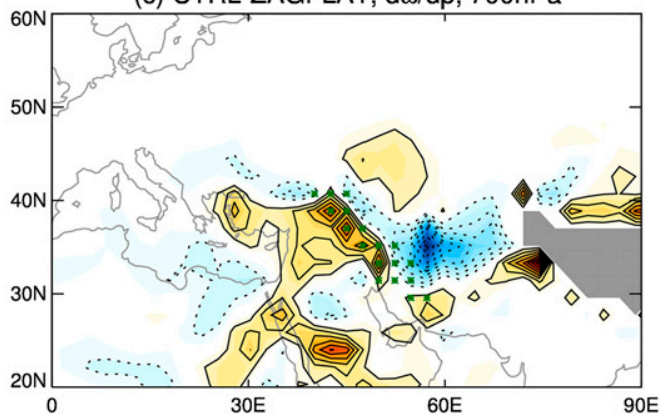

(e) CTRL-ZAGFLAT, 330K isentrope $p$

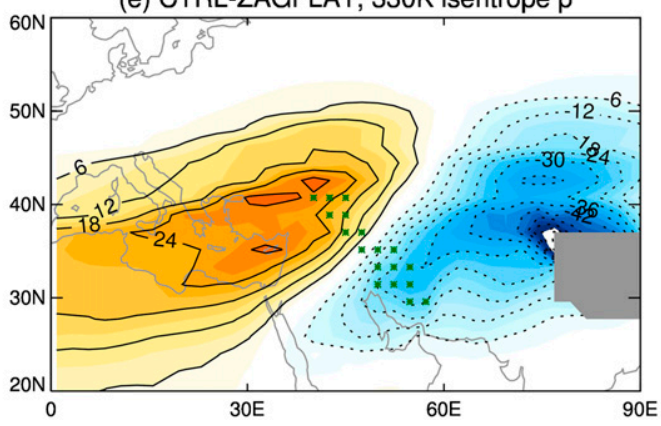

(b) ZAGFLAT $\theta$ (45E)

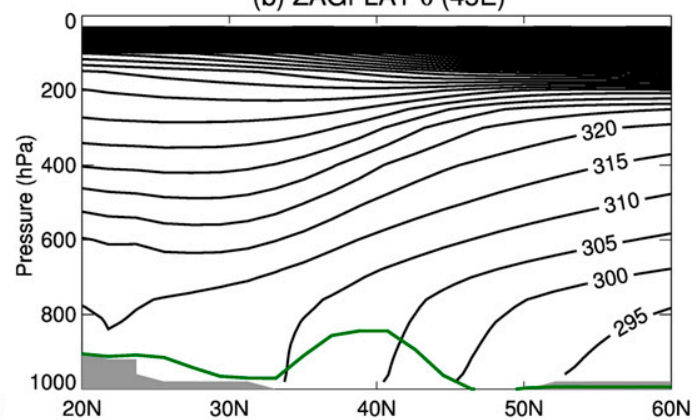

(d) CTRL-ZAGFLAT, $\zeta, 700 \mathrm{hPa}$

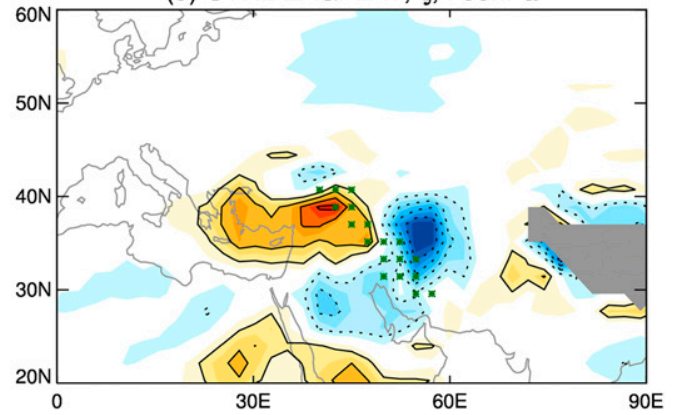

(f) CTRL-ZAGFLAT, $\Phi, 39 \mathrm{~N}$

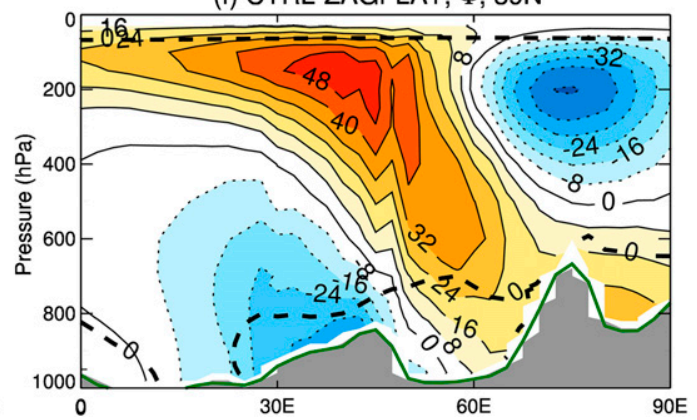

FIG. 7. Various fields that aid in the interpretation of the Zagros Mountain response: (a) a zonal cross section of zonal wind along $39^{\circ} \mathrm{N}$ and (b) a meridional cross section of potential temperature along $45^{\circ} \mathrm{E}$ for the basic state (i.e., the ZAGFLAT simulation). Green lines show the CTRL surface pressure. CTRL - ZAGFLAT anomalies (i.e., the Zagros Mountain influence) with green points indicating grid points where the surface is above $1.2 \mathrm{~km}$, (c) $\partial \omega / \partial p$ at $700 \mathrm{hPa}$ (contour interval $=6 \times 10^{-7} \mathrm{~s}^{-1}$ ), (d) relative vorticity at $700 \mathrm{hPa}$ (contour interval $=4 \times$ $10^{-6} \mathrm{~s}^{-1}$ ), and (e) the anomalous pressure of the 330-K isentrope in hectopascals. (f) A zonal cross section of CTRL ZAGFLAT geopotential height anomalies along $39^{\circ} \mathrm{N}$. Gray shading denotes regions where the pressure level is below the surface. Note that the Zagros Mountains in (a),(b) are located where gray shading is absent under the green contour.

seen in Fig. 4b. The thermodynamic balance of the anomalous low-level $(700 \mathrm{hPa})$ circulation confirms that the flow is approximately adiabatic with meridional advection balancing adiabatic warming/cooling. In a steady state and without changes in the diabatic heating and transients, the thermodynamic balance of the anomalies in the presence of the mountain is given by

$0=-\Delta\left(\left.\frac{u}{a \cos \phi} \frac{\partial T}{\partial \lambda}\right|_{p}\right)-\Delta\left(\left.\frac{v}{a} \frac{\partial T}{\partial \phi}\right|_{p}\right)-\Delta\left[\left(\frac{p}{p_{o}}\right)^{\kappa} \omega \frac{\partial \theta}{\partial p}\right]$, where $\Delta$ refers to the CTRL - ZAGFLAT difference in climatologies; $u, v, T, \theta$, and $\omega$ are the zonal wind, meridional wind, temperature, potential temperature, and pressure vertical velocity at pressure level $p ; p_{o}$ is a reference pressure $(1000 \mathrm{hPa})$; and $\lambda, \phi$, and $a$ are longitude, latitude, and radius of Earth, respectively. The three terms represent zonal advection, meridional advection, and vertical advection (or adiabatic warming/ cooling) of temperature, respectively. Figures $9 a-c$ show these three components at $700 \mathrm{hPa}$. They balance well and the dominant balance is between the meridional and 


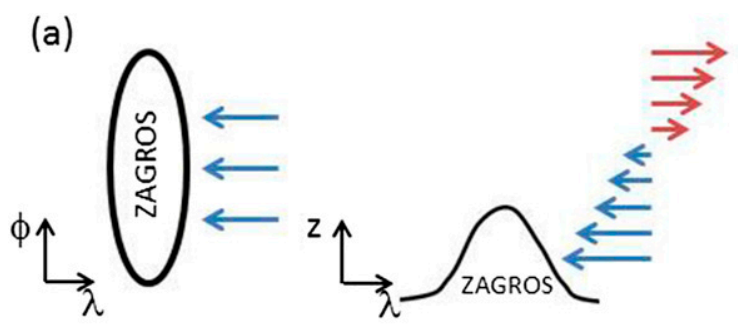

(b)

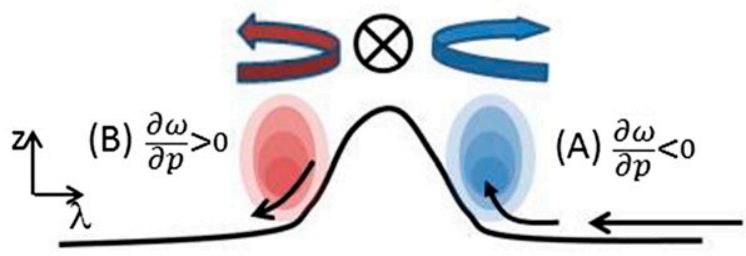

(c)

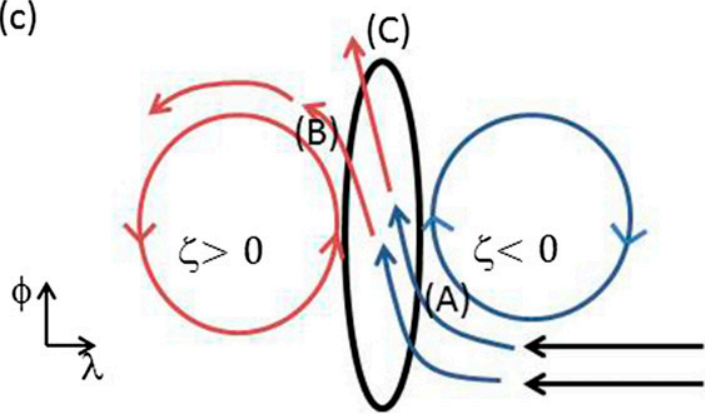

FIG. 8. Schematic depiction of the influence of the Zagros Mountains on the circulation. (a) The basic state zonal flow incident on the mountains from above and from the south. (b) A view from the south of the mountain influence. Black arrows show the flow; blue and red shading show upward and downward vertical velocity, respectively; and blue and red arrows show anticyclonic and cyclonic vorticity, respectively. Circle and crosshairs indicates southerly flow along the axis of the range. (c) A view from above of the mountain influence. Blue is on the upslope, and red is on the downslope. See text for the meaning of points A-C.

vertical advection terms. The linearized version of (2) (not shown) indicates that the dominant balance at low levels is

$$
0 \approx-\frac{v^{\prime}}{a} \frac{\partial \bar{T}}{\partial \phi}-\left(\frac{p}{p_{o}}\right)^{\kappa} \omega^{\prime} \frac{\partial \bar{\theta}}{\partial p}
$$

where $(\cdot)^{\prime}$ represents the CTRL - ZAGFLAT anomalies and $\overline{(\cdot)}$ represents the ZAGFLAT basic state. This confirms that, for the most part, the anomalous flow in the lower troposphere is gliding adiabatically along the meridionally sloping isentropes with equatorward flow and cold advection balanced by adiabatic subsidence and warming. The anomalous subsidence over the central to eastern Mediterranean in the lower troposphere is, therefore, a consequence of the anomalous meridional flow that is set up by the Zagros Mountains.

In the upper troposphere, Figs. $9 \mathrm{~d}-\mathrm{f}$ reveal a more complicated thermodynamic balance. The anomalous poleward meridional wind along the Zagros range is present in the upper troposphere as well but is more localized to the northern most edge of the range (Fig. 4e). The meridional warm advection associated with this flow is balanced, to some extent, by vertical advection. However, this balance is incomplete, and the zonal advection term is now playing an important role (Fig. 9d). A warm anomaly develops to the northwest of the mountains (not shown) with resultant anomalies in the zonal advection term as the midlatitude westerlies interact with it, and the dominant balance of terms here is

$$
0 \approx-\frac{\bar{u}}{a \cos \phi} \frac{\partial T^{\prime}}{\partial \lambda}-\frac{v^{\prime}}{a} \frac{\partial \bar{T}}{\partial \phi}-\left(\frac{p}{p_{o}}\right)^{\kappa} \omega^{\prime} \frac{\partial \bar{\theta}}{\partial p} .
$$

The upper-tropospheric subsidence over the Mediterranean is related to the interaction of the climatological midlatitude westerly flow with the mountain-induced temperature anomaly. The warm thermal anomaly results in an increased sloping of the isentropes as can be seen in Fig. 7e, which shows the Zagros Mountains influence on the pressure of the $330-\mathrm{K}$ isentrope. Climatologically, this isentrope slopes meridionally down toward the warm Asian monsoon region. In the presence of the mountains, the pressure level of this isentrope is lowered over the central to eastern Mediterranean and, as a result, the isentropic slope to the north of this has been steepened. Therefore, the midlatitude westerlies will experience enhanced subsidence as they flow along these steeper isentropes. This is the same as the arguments of RH96 for widespread monsoon-induced Mediterranean and Saharan subsidence, but here an additional thermal anomaly is generated in the presence of the mountains, which steepens the isentropes over the region further. So, while the Zagros Mountains result in a somewhat vertically coherent enhanced subsidence over the central to eastern Mediterranean, the subsidence anomalies in the upper and lower troposphere are produced for slightly different reasons with the balance of terms gradually transitioning between the regime found in the lower troposphere to that found in the upper troposphere.

Figure $7 \mathrm{f}$ shows a longitude-pressure cross section of the geopotential height anomalies induced by the Zagros Mountains along $39^{\circ} \mathrm{N}$. The negative and positive anomalies on either side of the mountains exhibit a westward tilt with height indicating vertical Rossby wave propagation. While the incident flow on the mountains is easterly, this 
(a) $700 \mathrm{hPa}$ zonal advection

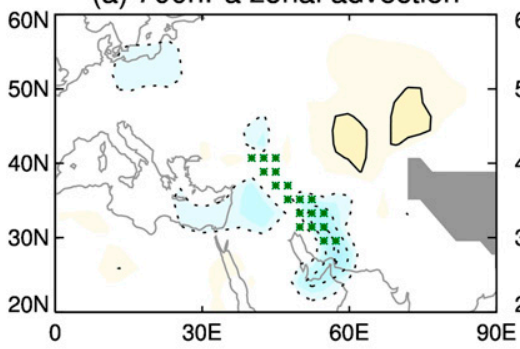

(d) $300 \mathrm{hPa}$ zonal advection

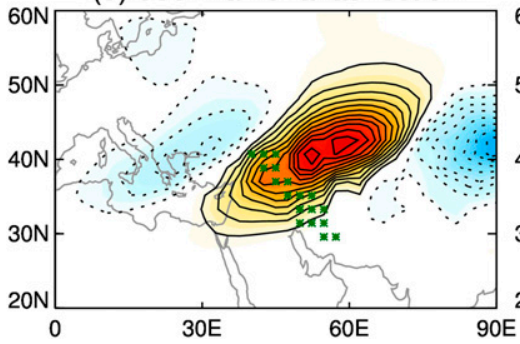

(b) $700 \mathrm{hPa}$ meridional advection

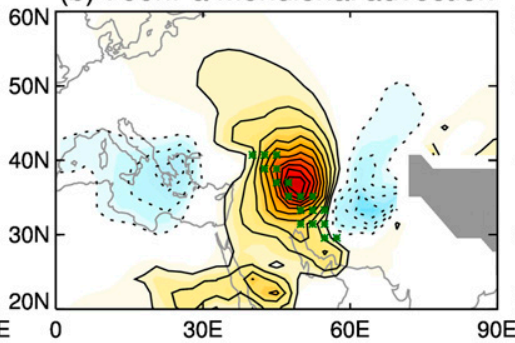

(e) $300 \mathrm{hPa}$ meridional advection (c) $700 \mathrm{hPa}$ vertical advection

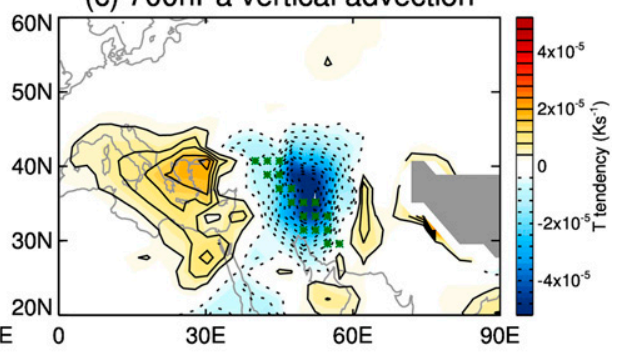

(f) $300 \mathrm{hPa}$ vertical advection

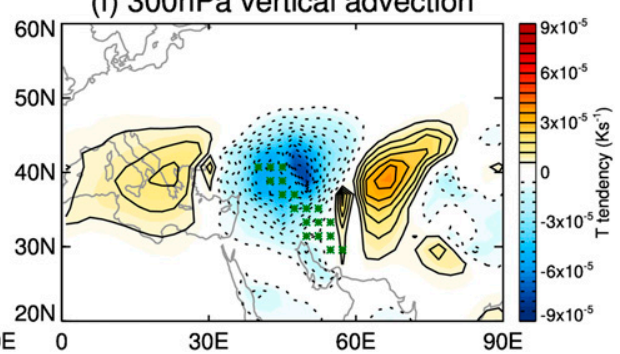

FIG. 9. CTRL - ZAGFLAT difference for the three thermodynamic budget terms in (2) at (a)-(c) 700 and (d)-(f) $300 \mathrm{hPa}$. Green points indicate Zagros grid points that are above $1.2 \mathrm{~km}$, and gray shading denotes regions that are below the surface.

transitions to westerlies within the lower troposphere (Fig. 7a), which provides favorable conditions for the vertical propagation of the wave activity induced at low levels into the upper troposphere, resulting in the uppertropospheric Rossby wave structures that are then advected toward the east along the Asian jet.

\section{The topography influence in other seasons}

The focus so far has been on the summer (JJA) months as this is the season when subsidence over the Mediterranean is strong, because of the Asian monsoon influence (RH96). This is also the season when the mountains have the greatest effect on Mediterranean subsidence, as can be seen in Fig. 10. In the winter [December-February (DJF)], the 500-hPa subsidence over the region is fairly longitudinally symmetric and shifted south compared to JJA (not shown). It is no longer strong over the Mediterranean and primarily represents the subsiding branch of the Hadley cell. The low-level winds that are incident on the Zagros Mountains in this season are westerly (Fig. 10a).

Figure $10 \mathrm{~b}$ shows the $500-\mathrm{hPa} \omega$ response to the presence of the Zagros Mountains in DJF: that is, the CTRL ZAGFLAT anomalies. The Zagros Mountains have very little influence on subsidence over the Mediterranean in this season and also do not produce the large-amplitude upper-level wave train that extends to the east (not shown). Instead, the influence of the Zagros Mountains is largely restricted to the local region in which the topography is flattened. While noisy, there is an indication of enhanced southerly ascending flow on the western slopes and subsiding northerly flow on the eastern slopes (see Fig. 10b for $\omega)$. This is what would be expected from adiabatic flow from the west going up and over the mountains in the presence of the meridional temperature gradient.

The seasonal cycle of daily mean vertical velocity at $500 \mathrm{hPa}$ averaged over the central to eastern Mediterranean, where in JJA the Zagros Mountains have the greatest influence on subsidence, is shown in Fig. 10c for CTRL and ZAGFLAT. This demonstrates that the Zagros Mountains only have a significant influence on Mediterranean subsidence during the summer months, from June until the end of September. Furthermore, Fig. 10d shows the low-level $(850 \mathrm{hPa})$ zonal wind over the location of the Zagros Mountains for the ZAGFLAT simulation: that is, the winds that would be incident on the mountains if the mountains were not there. Comparison of this with Fig. 10c indicates that the Zagros Mountains only have a substantial influence on Mediterranean subsidence when the low-level winds incident on them are from the east (i.e., the summer). A perfect correspondence between the enhanced $\omega$ and the magnitude of the easterlies is not necessarily expected because the $\omega$ anomalies also involve interaction between the mountain-induced circulation and the midlatitude westerlies, which have a seasonal variation themselves. However, it is clear that it is only when the incident flow is easterly that enhanced Mediterranean subsidence is produced. The winter westerlies, which are of a similar magnitude, do not result in a visible influence on Mediterranean subsidence via topographic interaction. 
(a) DJF, ZAGFLAT, 850hPa wind vectors

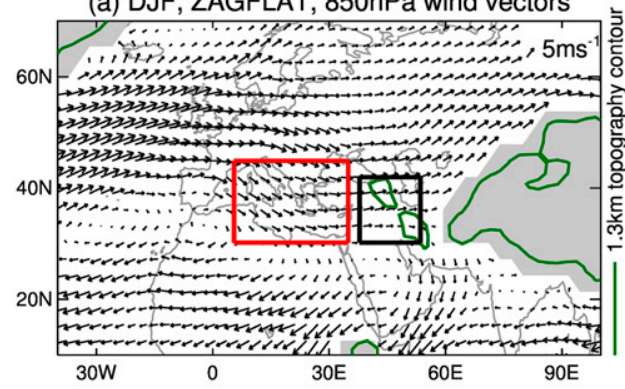

(b) CTRL-ZAGFLAT, $500 \mathrm{hPa} \omega$

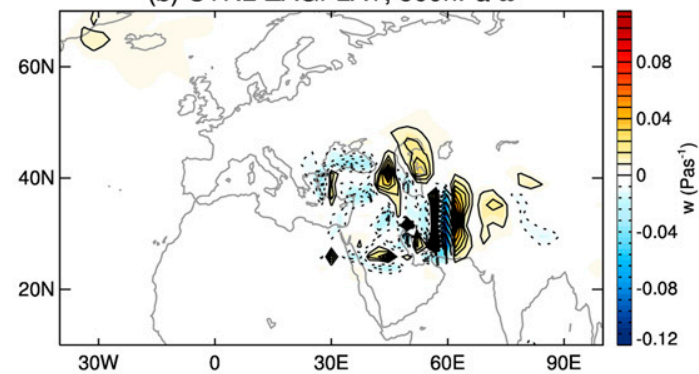

(c) Mediterranean averaged 500hpa vertical velocity

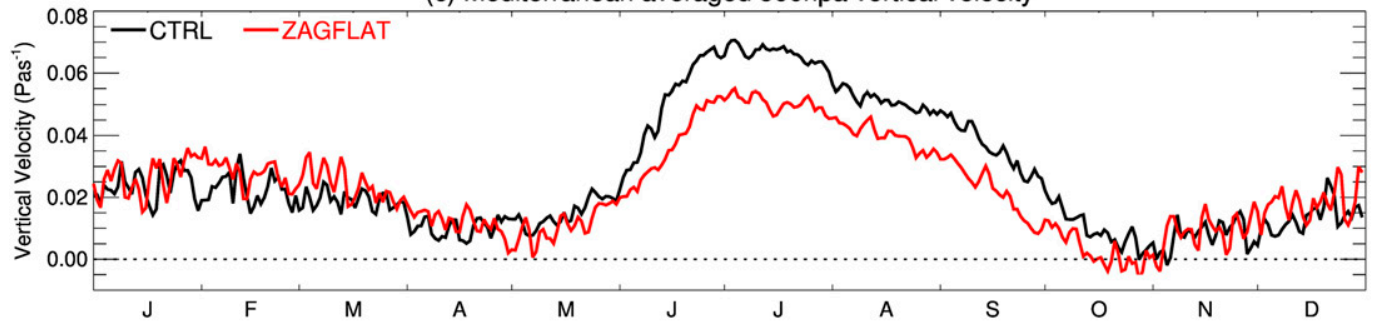

(d) Zonal wind across the Zagros mountan location in ZAGFLAT at $850 \mathrm{hPa}$

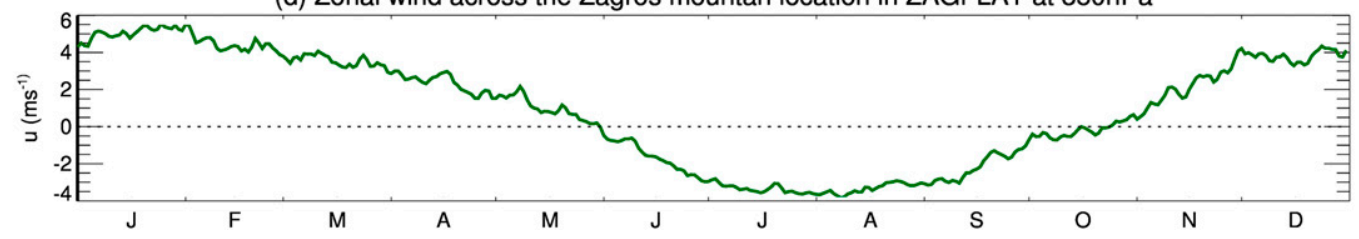

FIG. 10. (a) DJF averaged $850-\mathrm{hPa}$ wind vectors with the red box denoting the region used for averaging 500-hPa $\omega$ in (c) and the black box denoting the region for averaging 850-hPa $u$ in (d). (b) The Zagros influence (CTRL ZAGFLAT) on 500-hPa $\omega$ during DJF. (c) The seasonal evolution of daily 500-hPa $\omega$ averaged over the red box in (a). (d) The seasonal evolution of 850 -hPa $u$ averaged over the black box in (a).

\section{The role of condensational heating in generating the summertime incident easterly flow on the Zagros Mountains}

The above analysis suggests that the presence of easterly incident flow during the summer is key to producing the Zagros Mountain influence on the Mediterranean. This then raises the question, what is responsible for the easterly incident flow on the Zagros Mountains during the summer? In Fig. 11, additional experiments with the stationary wave model are shown to address this question. Rather than imposing the Zagros Mountains in the 3D ZAGFLAT basic state, as done in section 5a, the stationary wave model is used to build up the $3 \mathrm{D}$ flow from scratch. The first experiment uses the ZAGFLAT zonal mean basic state and the ZAGFLAT diabatic heating; ZAGFLAT topography; and ZAGFLAT transient vorticity, divergence, and heat fluxes are imposed. The $850-\mathrm{hPa}$ wind vectors of the resulting flow are shown in Fig. 11a. This can be compared with the actual ZAGFLAT low-level winds in Fig. 6a. The winds are not perfectly reproduced, because of the idealized nature of the experiments but the low-level easterly flow that is incident on the Zagros Mountains is reproduced rather well, albeit a little too strong. A second experiment is then performed imposing ZAGFLAT diabatic heating, CTRL topography, and ZAGFLAT transient fluxes: that is, the only difference between the second and first experiments is the presence of the Zagros Mountains. The difference between these experiments reproduces the Zagros Mountain influence rather well, as can be seen by comparison of the $700-\mathrm{hPa}$ meridional wind anomalies in Fig. 11b with those in Fig. 6d. Since building the stationary wave model circulation from scratch in this manner reproduces the summertime incident easterlies and the Zagros response, it can be used to identify what is responsible for these.

Two additional experiments are performed, equivalent to the previous ones except that the condensational heating $\left(Q_{\mathrm{COND}}\right)$ over Asia, the Indian Ocean, and the western Pacific $\left(60^{\circ}-150^{\circ} \mathrm{E}, 0^{\circ}-60^{\circ} \mathrm{N}\right)$ is removed. ${ }^{3}$ Figures $11 \mathrm{c}, \mathrm{d}$ show the influence of the

\footnotetext{
${ }^{3}$ Condensational heating was not removed in the lowest two sigma levels because the CAM5 diabatic heating output consists of large negative condensational heating values at the surface that largely balance a warming tendency because of vertical diffusion.
} 
(a) Full Q, 850hPa winds

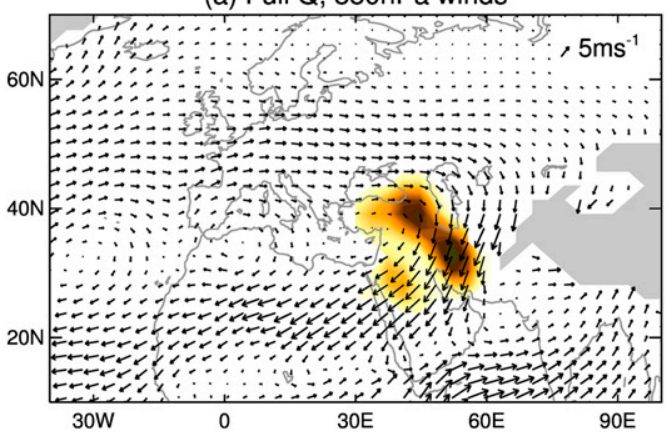

(c) Asian $\mathrm{Q}_{\text {cond }}$ influence on $850 \mathrm{hPa}$ winds

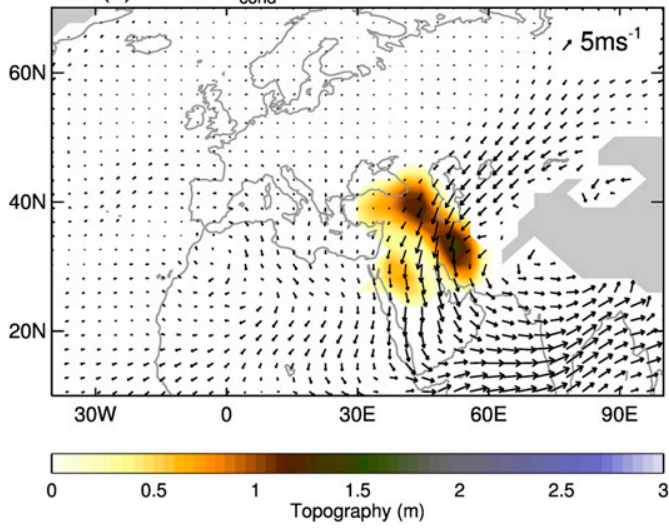

(b) Zagros response, with full Q (700hPa v)

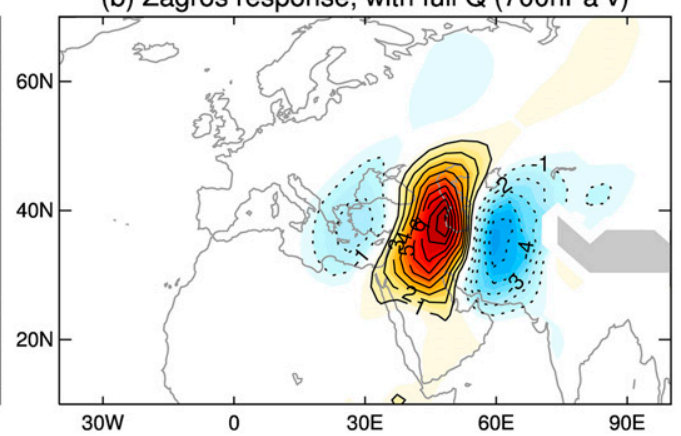

(d) Asian $Q_{\text {cond }}$ influence on Zagros response (700hPa v)

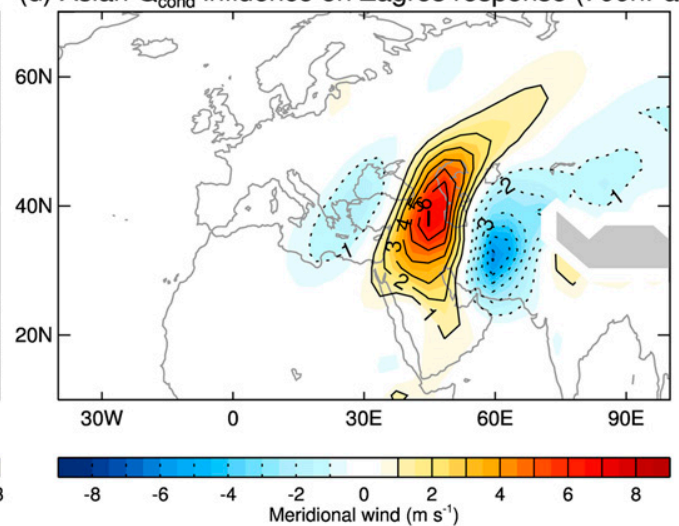

FIG. 11. The result of stationary wave model experiments described in section 7: (left) 850-hPa wind vectors in simulations with the ZAGFLAT topography and (right) 700-hPa meridional wind difference between simulations with CTRL topography and simulations with ZAGFLAT topography (i.e., the Zagros Mountain influence). All simulations are run with the prescribed zonal mean basic state of the ZAGFLAT simulation and ZAGFLAT transient vorticity fluxes. (top) The full ZAGFLAT diabatic heating is imposed. (bottom) The difference between (top) and equivalent experiments in which the condensational component of the heating $Q_{\text {COND }}$ was removed from $60^{\circ}$ to $150^{\circ} \mathrm{E}$ and $0^{\circ}$ from $60^{\circ} \mathrm{N}$. The shading in (left) is the CTRL - ZAGFLAT topography, and gray shading denotes regions below the surface.

Asian $Q_{\text {COND }}$ on the flow (i.e., the difference between the experiments with the full heating and those with the Asian $Q_{\text {COND }}$ omitted). Figure $11 \mathrm{c}$ shows that the Asian $Q_{\mathrm{COND}}$ is largely responsible for the easterlies that are incident on the Zagros Mountains, which is in agreement with similar idealized experiments performed by Liu et al. (2007). The incident easterlies are part of the low-level cyclonic circulation set up by the heating over Asia. Figure 11d demonstrates that much of the Zagros Mountain-induced tripole in 700-hPa $v$ is only produced when the Asian $Q_{\text {COND }}$ heating is present.

Additional experiments performed with the Asian topography removed (not shown) further indicate that the influence of $Q_{\mathrm{COND}}$ on the low-level flow is modified by the presence of the Asian topography. With the Asian topography removed, the low-level cyclone is confined toward the south and no longer results in incident easterlies for the Zagros Mountains.

\section{Discussion}

The earlier idealized modeling experiments of RH96 noted a role for the Atlas Mountains in localizing Mediterranean subsidence during the summer but found that the Middle East mountains only had an effect to their east, with very little impact on the Mediterranean. In contrast, the results presented here, using a full GCM, demonstrate an important influence of Middle East topography (primarily the Zagros mountain range) on the subsidence over the Mediterranean during the summer, with a relatively minor contribution from the Atlas Mountains.

Here, the mountain influence was demonstrated using a comprehensive GCM but the Zagros Mountains influence was also reproduced in a stationary wave model using a similar methodology to RH96 (see section 7), and it is not clear why our stationary wave model results should differ. A similar influence of the mountains was 
also produced in our stationary wave model when the imposed diabatic heating was calculated as a residual from ERA-Interim. The RH96 discussion assumed that the incident flow on the mountain ranges was westerly, although this was not explicitly shown and so it is unclear whether this was indeed the case. The flow in their simulation with the mountains present does, however, exhibit easterlies at the Zagros location (RH96, their Fig. 3a), and RH01 (their Fig. 9) and Liu et al. (2007) (their Fig. 2f) demonstrated, with the same model, that Asian monsoon heating also produces low-level easterlies over the Zagros location in that model too. We can only speculate that the results differ because of differences in the stationary wave model setup or differences in the input forcings. RH96's heating and basic state were obtained from a much shorter period, and it is possible that this produced different incident flows, resulting in a difference in the relative importance of the Atlas Mountains as compared to the Zagros Mountains. Indeed, the CAM5 results indicate that both mountain ranges are capable of inducing subsidence in the central to eastern Mediterranean during the summer when they both experience easterly incident flow. In fact, by chance, the two mountain ranges are separated in longitude by just the right amount that they both conspire to intensify subsidence and low-level northerly winds in a similar location. It is conceivable that under a different basic state the Atlas Mountains could dominate.

The results presented here are only for one comprehensive GCM, but it is one that reproduces the main features of the Mediterranean circulation, as well as the upper-level wave train that extends to the east of the Zagros Mountains. One aspect of the model fidelity that could be of concern is the fact that the low-level flow over Mesopotamia/Saudi Arabia is poorly simulated (cf. Figs. 2g,h). This aspect of the circulation is much improved in CAM5 at $0.9^{\circ} \times 1.25^{\circ}$ resolution, and preliminary investigation at that resolution indicates that the same conclusions as to the Middle East topography influence on the large-scale circulation can be drawn (not shown). This discrepancy in the flow therefore likely does not represent a discrepancy in the incident flow for the mountains but rather a discrepancy in the responding flow in the lee of the mountains on this more regional scale where the topography is poorly resolved. Given this and the fidelity of the lower-resolution model circulation both over the Mediterranean and toward the east over Eurasia, we expect that the results are relevant for the real atmosphere.

It has been demonstrated that the mountains exert their influence primarily through their mechanical effect on the mean flow and a discussion of the mechanism by which this effect is realized has been provided. In particular, we have clarified that, contrary to what is often assumed when discussing the topographic influence of the region (e.g., RH96; Tyrlis et al. 2013), the relevant low-level incident mean flow to consider in summer is actually easterly. It is important to consider the incident flow as being the flow without the mountain influence already in it, which obviously cannot be assessed completely in the real world. The presence of easterly incident flow appears to be key for producing the mountain influence and, for the case of the Zagros Mountains, this is set up during the summertime by the presence of enhanced condensational heating over Asia with additional modification by the Asian topography. The result is easterly winds that skirt the northern flank of the Tibetan plateau (Fig. 11c) before hitting the Zagros Mountains.

It is worth contrasting the influence of these smaller subtropical mountain ranges with the larger mountain ranges that exist in the midlatitudes, such as the Rockies and the Andes. RH01 suggest that the influence of these larger mountain ranges is greater during the winter, when stronger westerly winds are incident on them. They also found that nonlinear dynamics need to be considered (i.e., the blocking of the flow by the mountains) to explain their influence. In contrast, for the Zagros Mountains, their influence is greatest during the summer when the low-level incident flow is easterly, and nonlinear dynamics is not necessary to explain their effect during the summer. It is also worth noting that, while RH01 (their Fig. 10c) suggest that during the winter topography also results in a bull's-eye of subsidence over the eastern Mediterranean, their topography influence was inferred by placing the topography in the zonal mean basic state. To infer the true influence of topography, it is necessary to place the topography in the incident flows that are set up by the diabatic heating and transient vorticity fluxes, and in this case, as shown here with the comprehensive GCM, the Zagros Mountains have very little influence on Mediterranean subsidence during the winter and only results in small vertical velocity anomalies in the vicinity of the mountains.

When easterly mean flow impinges on the Zagros Mountains, a low-level anticyclone is produced on the upslope and a low-level cyclone is produced on the downslope, resulting in a tripole pattern in low-level meridional wind and vertical velocity, centered on the longitude of the mountain range. The same is also true for the Atlas Mountains, which also experience easterly incident flow in summer, and Semazzi and Sun (1997) already recognized such a pattern for this range. The perturbations induced by the mountains in these lowlevel easterlies appear to be substantial enough to 
produce a vertically propagating Rossby wave structure and an associated wave train that extends toward the east. For the case of the Zagros Mountains, in the upper troposphere, the interaction of the midlatitude westerlies, with the warm anomaly associated with the mountain-induced circulation, contributes to the Mediterranean subsidence. This discussion adds to an already extensive body of literature on the subject of the influence of mountain ranges on the mean flow.

The fact that the Zagros Mountains only appear to exert a substantial influence on the large-scale mean flow when the low-level incident flow is easterly is somewhat surprising, and it is not obvious why there should be this asymmetry. While the beta effect introduces some asymmetry between westerly and easterly incident flow, it is likely that the most important factor in breaking the symmetry for the Zagros Mountains is the presence of the meridional temperature gradient. For easterly incident winds, the upslope vortex compression encourages the northward movement of the flow, which is also required by thermodynamic considerations if it is to go up and over the mountains adiabatically. For westerly flow, vorticity arguments would predict turning toward the south on the upslope but thermodynamic arguments would require adiabatic upward motion to flow north. It may be that, for easterly flow, these two factors work together to produce a much stronger response than for westerly flow where they are conflicting. However, the details of this asymmetry and the sensitivity to incident flows and mountain size and shape are something that warrants further investigation with idealized experiments.

\section{Conclusions}

As we head toward a warmer climate in which the Mediterranean is predicted to undergo substantial change, it is important that we have a complete understanding of the dynamical processes that govern the climate of the region. This motivates better understanding of the topographic influence on the circulation and climate of the Mediterranean. These comprehensive GCM experiments demonstrate that both the topography of the Middle East and North Africa conspire to produce about $30 \%$ of the summertime subsidence over the central to eastern Mediterranean in the current climate but it is the contribution from the Middle East topography that dominates in this topographic influence by far. This topography, primarily the Zagros mountain range, influences the large-scale circulation throughout the depth of the troposphere and affects the upper-level circulation across the whole of the Eurasian continent during the summer, when the incident flow is easterly. In contrast, during the winter, when the incident flow is westerly, these mountains have very little impact on the large-scale circulation.

The use of a comprehensive GCM has allowed us to make some statements as to the climatological impact of the mountains on the Mediterranean. Semiarid conditions are found in the Mediterranean during the summer with a moisture deficit associated with substantial evaporation and very little precipitation. The model results suggest that on average, around $20 \%$ of this moisture deficit-and in some regions more-can be attributed to the presence of the Zagros Mountains and the circulation they induce. The effect of the Zagros Mountains on the circulation is therefore an important contributor to the climatological conditions of the Mediterranean during the summer.

Finally, one question that the results raise is, given the importance of these mountains for the current climate of the Mediterranean, do they contribute substantially to future predicted changes in Mediterranean circulation under increasing anthropogenic greenhouse gas emissions? The Mediterranean is often identified as a climate change "hotspot," referring to the fact that it is predicted to undergo larger hydroclimate and circulation changes in the future than many other regions of the globe (Giorgi 2006; Giorgi and Lionello 2008; Seager et al. 2014; Simpson et al. 2014). It is possible that interaction between the altered mean flow and the mountains plays a role in future circulation changes in the region and this is a subject that is under current investigation.

Acknowledgments. IRS is grateful to Dr. Gus Correa for advice in the setup of the CAM5 simulations and to Dr. Naomi Henderson for advice in the setup of the stationary wave model. IRS was supported by a LamontDoherty Earth Observatory Postdoctoral Fellowship and NSF Award AGS-1317469. RS and MT were supported by NOAA Award NA10OAR4310137 ("Global decadal hydroclimate variability and change") and DOE Award DE-SC0005107. TAS is supported by NSF Award AGS-1255208 and the David and Lucile Packard Foundation. We would also like to thank two anonymous reviewers for helpful comments on this manuscript.

\section{REFERENCES}

Alpert, P., B. U. Neeman, and Y. Shay-El, 1990: Climatological analysis of Mediterranean cyclones using ECMWF data. Tellus, 42A, 65-77, doi:10.1034/j.1600-0870.1990.00007.x.

Black, E., D. Brayshaw, J. Slingo, and B. J. Hoskins, 2011: Future climate of the Middle East. Water, Life and Civilisation: Climate, Environment and Society in the Jordan Valley, S. Mithen and E. Black, Eds., Cambridge University Press, 51-62. 
Boos, W. R., and Z. Kuang, 2010: Dominant control of the South Asian monsoon by orographic insulation versus plateau heating. Nature, 463, 218-222, doi:10.1038/nature08707.

Charney, J. G., and A. Eliassen, 1949: A numerical method for predicting the perturbations of the middle latitude westerlies. Tellus, 1, 38-54, doi:10.1111/j.2153-3490.1949.tb01258.x.

Cook, K. H., and I. M. Held, 1992: The stationary response to large-scale orography in a general circulation model and a linear model. J. Atmos. Sci., 49, 525-539, doi:10.1175/ 1520-0469(1992)049<0525:TSRTLS $>2.0$.CO;2.

Dee, D. P., and Coauthors, 2011: The ERA-Interim reanalysis: Configuration and performance of the data assimilation system. Quart. J. Roy. Meteor. Soc., 137, 553-597, doi:10.1002/ qj.828.

Dickinson, R. E., 1978: On planetary waves. The General Circulation: Theory, Modeling and Observations: Notes from a Colloquium, Summer 1978, M. L. Blackmon and R. Gall, Eds., National Center for Atmospheric Research, 59-82.

Evans, J. P., 2009: 21st century climate change in the Middle East. Climatic Change, 92, 417-432, doi:10.1007/s10584-008-9438-5.

Fernández, J., J. Sáenz, and E. Zorita, 2003: Analysis of wintertime atmospheric moisture transport and its variability over southern Europe in the NCEP reanalysis. Climate Res., 23, 195-215, doi:10.3354/cr023195.

Gill, A. E., 1980: Some simple solutions for heat-induced tropical circulation. Quart. J. Roy. Meteor. Soc., 106, 447-462, doi:10.1002/ qj. 49710644905 .

Giorgi, F., 2006: Climate change hot-spots. Geophys. Res. Lett., 22, L08707, doi:10.1029/2006GL025734.

, and P. Lionello, 2008: Climate change projections for the Mediterranean region. Global Planet. Change, 63, 90-104, doi:10.1016/j.gloplacha.2007.09.005.

Grose, W. L., and B. J. Hoskins, 1979: On the influence of orography on large scale atmospheric flow. J. Atmos. Sci., 36, 223-234, doi:10.1175/1520-0469(1979)036<0223:OTIOOO >2.0.CO;2.

Held, I. M., M. Ting, and H. Wang, 2002: Northern winter stationary waves: Theory and modeling. J. Climate, 15, 2125-2144, doi:10.1175/1520-0442(2002)015<2125:NWSWTA > 2.0.CO;2.

Hoerling, M., J. Eischeid, J. Perlwitz, X. Quan, T. Zhang, and P. Pegion, 2012: On the increased frequency of Mediterranean drought. J. Climate, 25, 2146-2161, doi:10.1175/JCLI-D-11-00296.1.

Holton, J. R., 2004: An Introduction to Dynamic Meteorology. 4th ed. Academic Press, 535 pp.

Hoskins, B. J., and D. J. Karoly, 1981: The steady linear response of a spherical atmosphere to thermal and orographic forcing. $J$. Atmos. Sci., 38, 1179-1196, doi:10.1175/1520-0469(1981)038<1179: TSLROA $>2.0 . \mathrm{CO} ; 2$.

Hurrell, J. W., 1995: Decadal trends in the North Atlantic Oscillation: Regional temperatures and precipitation. Science, 269, 676-679, doi:10.1126/science.269.5224.676.

—_, and Coauthors, 2013: The Community Earth System Model: A framework for collaborative research. Bull. Amer. Meteor. Soc., 94, 1339-1360, doi:10.1175/BAMS-D-12-00121.1.

Lionello, P., and Coauthors, 2006: The Mediterranean climate: An overview of the main characteristics and issues. Mediterranean Climate Variability, P. Lionello, P. Malanotte-Rizzoli, and R. Boscolo, Eds., Elsevier, 1-26.

Liu, Y., B. Hoskins, and M. Blackburn, 2007: Impact of Tibetan orography and heating on the summer flow over Asia. J. Meteor. Soc. Japan, 85B, 1-19, doi:10.2151/jmsj.85B.1.

Mariotti, A., M. V. Struglia, N. Zeng, and K.-M. Lau, 2002: The hydrological cycle in the Mediterranean region and implications for the water budget of the Mediterranean Sea.
J. Climate, 15, 1674-1690, doi:10.1175/1520-0442(2002)015<1674: THCITM $>2.0 . \mathrm{CO} ; 2$.

Quadrelli, R., V. Pavan, and F. Molteni, 2001: Wintertime variability of Mediterranean precipitation and its links with large scale circulation anomalies. Climate Dyn., 17, 457-466, doi:10.1007/s003820000121.

Ringler, T. D., and K. H. Cook, 1997: Factors controlling nonlinear in mechanically forced stationary waves over orography. J. Atmos. Sci., 54, 2612-2629, doi:10.1175/1520-0469(1997)054<2612: FCNIMF $>2.0 . \mathrm{CO} ; 2$

Rodwell, M. J., and B. J. Hoskins, 1996: Monsoons and the dynamics of deserts. Quart. J. Roy. Meteor. Soc., 122, 1385-1404, doi:10.1002/qj.49712253408.

$\longrightarrow$, and - 2001: Subtropical anticyclones and summer monsoons. J. Climate, 14, 3192-3211, doi:10.1175/1520-0442(2001)014<3192: $\mathrm{SAASM}>2.0 . \mathrm{CO} ; 2$.

Seager, R., H. Liu, N. Henderson, I. R. Simpson, C. Kelley, T. A. Shaw, Y. Kushnir, and M. Ting, 2014: Causes of increasing aridification of the Mediterranean region in response to rising greenhouse gases. J. Climate, 27, 4655-4676, doi:10.1175/ JCLI-D-13-00446.1.

Semazzi, F. H. M., 1980: Stationary barotropic flow induced by a mountain over a tropical belt. Mon. Wea. Rev., 108, 922-930, doi:10.1175/1520-0493(1980)108<0922:SBFIBA > 2.0.CO;2.

_ Sahelian climate. Int. J. Climatol., 17, 581-596, doi:10.1002/ (SICI)1097-0088(199705)17:6<581::AID-JOC134>3.0.CO;2-E.

Simpson, I. R., T. A. Shaw, and R. Seager, 2014: A diagnosis of the seasonally and zonally varying midlatitude circulation response to global warming. J. Atmos. Sci., 71, 2489-2515, doi:10.1175/ JAS-D-13-0325.1.

Ting, M., and L. Yu, 1998: Steady response to tropical heating in wave linear and nonlinear baroclinic models. J. Atmos. Sci., 55, 3565-3582, doi:10.1175/1520-0469(1998)055<3565: SRTTHI $>2.0 . \mathrm{CO} ; 2$.

Trenberth, K. E., and S.-C. Chen, 1988: Planetary waves kinematically forced by Himalayan orography. J. Atmos. Sci., 45, 2934-2948, doi:10.1175/1520-0469(1988)045<2934: $\mathrm{PWKFBH}>2.0 . \mathrm{CO} ; 2$.

Trigo, I. F., T. D. Davies, and G. R. Bigg, 1999: Objective climatology of cyclones in the Mediterranean region. J. Climate, 12, 1685-1696, doi:10.1175/1520-0442(1999)012<1685: OCOCIT $>2.0 . \mathrm{CO} ; 2$.

Tyrlis, E., J. Lelieveld, and B. Steil, 2013: The summer circulation over the eastern Mediterranean and the Middle East: Influence of the South Asian monsoon. Climate Dyn., 40, 11031123, doi:10.1007/s00382-012-1528-4.

Valdes, P. J., and B. J. Hoskins, 1991: Nonlinear orographically forced planetary waves. J. Atmos. Sci., 48, 2089-2106, doi:10.1175/ 1520-0469(1991)048<2089:NOFPW>2.0.CO;2.

Zaitchik, B. F., J. P. Evans, and R. B. Smith, 2007: Regional impact of an elevated heat source: The Zagros Plateau of Iran. J. Climate, 20, 4133-4146, doi:10.1175/JCLI4248.1.

Zappa, G., L. C. Shaffrey, K. I. Hodges, P. G. Sansom, and D. B. Stephenson, 2013: A multimodel assessment of future projections of North Atlantic and European extratropical cyclones in the CMIP5 climate models. J. Climate, 26, 5846-5862, doi:10.1175/JCLI-D-12-00573.1.

Zarrin, A., H. Ghaemi, M. Azadi, A. Mofidi, and E. Mirzaei, 2011: The effect of the Zagros Mountains on the formation and maintenance of the Iran anticyclone using RegCM4. Meteor. Atmos. Phys., 112, 91-100, doi:10.1007/ s00703-011-0134-z. 